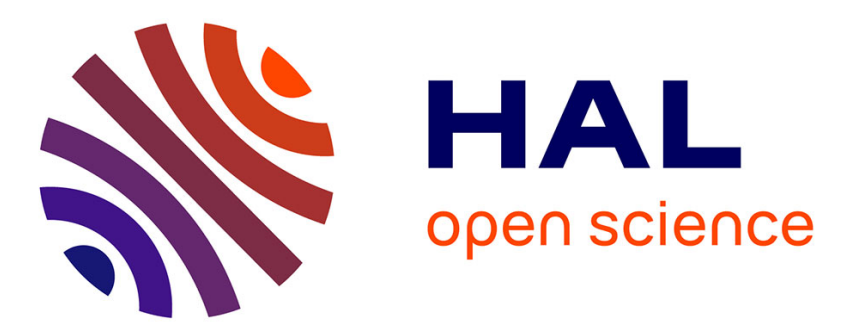

\title{
Influence of the Spark Plasma Sintering temperature on the structure and dielectric properties of $\operatorname{BaTi}(1-\mathrm{x}) \operatorname{ZrxO} 3$ ceramics
}

\author{
Blessing N. Ezealigo, Roberto Orrù, Catherine Elissalde, Hélène Debéda, \\ U-Chan Chung, Mario Maglione, Giacomo Cao
}

\section{To cite this version:}

Blessing N. Ezealigo, Roberto Orrù, Catherine Elissalde, Hélène Debéda, U-Chan Chung, et al.. Influence of the Spark Plasma Sintering temperature on the structure and dielectric properties of $\mathrm{BaTi}(1-\mathrm{x}) \mathrm{ZrxO} 3$ ceramics. Ceramics International, 2021, 47 (3), pp.3614-3625. 10.1016/j.ceramint.2020.09.210 . hal-02978411

\section{HAL Id: hal-02978411 \\ https://hal.science/hal-02978411}

Submitted on 26 Oct 2020

HAL is a multi-disciplinary open access archive for the deposit and dissemination of scientific research documents, whether they are published or not. The documents may come from teaching and research institutions in France or abroad, or from public or private research centers.
L'archive ouverte pluridisciplinaire HAL, est destinée au dépôt et à la diffusion de documents scientifiques de niveau recherche, publiés ou non, émanant des établissements d'enseignement et de recherche français ou étrangers, des laboratoires publics ou privés. 


\title{
Influence of the Spark Plasma Sintering temperature on the structure and dielectric properties of $\mathrm{BaTi}_{(1-\mathrm{x})} \mathrm{Zr}_{\mathrm{x}} \mathrm{O}_{3}$ ceramics
}

\author{
Blessing N. Ezealigo ${ }^{1}$, Roberto Orrù ${ }^{1, *}$, Catherine Elissalde ${ }^{2, *}$, Hélène Debéda ${ }^{3}$, U-Chan \\ Chung $^{2}$, Mario Maglione ${ }^{2}$, Giacomo $\mathrm{Cao}^{1}$
}

\begin{abstract}
${ }^{I}$ Dipartimento di Ingegneria Meccanica, Chimica e dei Materiali, Unità di Ricerca del Consorzio Interuniversitario Nazionale per la Scienza e Tecnologia dei Materiali (INSTM) - Università degli Studi di Cagliari, via Marengo 2, 09123 Cagliari, Italy

${ }^{2}$ Université de Bordeaux, CNRS, ICMCB, UMR 5026, 87 avenue du Dr A. Schweitzer, 33608 Pessac, France

${ }^{3}$ Université de Bordeaux, Laboratoire IMS, UMR 5218, 351 Cours de la Libération, 33405 Talence, Cedex, France
\end{abstract}

(*) Author to whom all correspondence should be addressed

Revised unmarked paper

September 2020 


\begin{abstract}
In this work, structural and dielectric properties of $\mathrm{BaTi}_{(1-\mathrm{x})} \mathrm{Zr}_{\mathrm{x}} \mathrm{O}_{3}(\mathrm{BTZ})$ ceramics prepared by Spark Plasma Sintering (SPS) from powders obtained via Self-propagating High-temperature Synthesis (SHS) are shown to be strongly affected by the sintering temperature. In addition, a postannealing treatment in air of the as-prepared ceramics leads to a transition from the hexagonal to the tetragonal and cubic phases. The SPS ceramics corresponding to compositions $0.05 \leq x \leq 0.20$ and obtained at a sintering temperature of $1200^{\circ} \mathrm{C}$ exhibit a standard ferroelectric behavior. In contrast, a diffuse phase transition is observed for the case of ceramics sintered at higher temperatures. Finally, the BTZ ceramic containing 5 at.\% of $\mathrm{Zr}$ displays the best dielectric permittivity and piezoelectric properties as compared to the other compositions taken into account.
\end{abstract}

Keyword: Dielectric permittivity, spark plasma sintering, piezoelectric, post-annealing; selfpropagating high-temperature synthesis.

Corresponding authors: roberto.orru@dimcm.unica.it, catherine.elissalde@icmcb.cnrs.fr 


\section{Introduction}

To meet specific applications, the strategy commonly adopted by the scientific community to improve the electrical characteristics of $\mathrm{ABO}_{3}$ perovskite materials is to change the ceramics' chemical content. Indeed, the substitution of the A or B cation sites with other isovalent ions can modify the material's dielectric properties, and lead to changes in the related transition temperatures as well as the formation of specific phases [1]. In this context, zirconium substituted barium titanate (BTZ) has attracted great attention in the last decade because of its wide range of applications, owing to its improved properties and potential to replace lead-based ferroelectric materials [2-3]. These properties include high dielectric permittivity, relatively low dielectric loss, large voltage tunability of the dielectric permittivity, good chemical stability, and attractive leadfree relaxor behavior [4-6].

In this regard, the marked influence of $\mathrm{Ti}$ sites substitution with $\mathrm{Zr}$ on the properties of the resulting BTZ ceramics obtained by conventional sintering has been addressed by various authors [7-9]. The BZT potential for application in tunable microwave devices has been demonstrated [10]. Specifically, it is reported that, when the amount of $\mathrm{Zr}$ content is within the range $0 \leq \mathrm{x} \leq 0.10$, the ceramics show a classical ferroelectric behavior [9, 11]. However, at higher $\mathrm{Zr}$ content, the ferroelectric phase coexists with the paraelectric one, leading to a diffuse phase transition. The latter one is promoted by the energy difference between the ferroelectric and the paraelectric phases [12]. Furthermore, the classical ferroelectric transitions of $\mathrm{BaTiO}_{3}$ continuously give rise to diffuse phase transition $(0.10<\mathrm{x} \leq 0.26)$ and relaxor state $(0.26<\mathrm{x} \leq 0.40)$, whose temperature of occurrence decreases to low values as the $\mathrm{Zr}$ content increases [13]. It is worth to mention that, in addition to the latter finding, the phase transition can also be influenced by temperature variation, depolarization due to presence of porosity, slight changes in the chemical potential, and 
grain size effect [12, 14-15]. A high dielectric permittivity of about 14,000 has been reported for dense BTZ ceramics $(x=0.08)$, which were produced by solid state reaction using high energy milling followed by conventional sintering [9].

Among the synthesis methods proposed to obtain BTZ powders, Sol-gel [16-17], Sol-gel based Pechini method [18], solid-state reactions [19-20], and combustion synthesis [21-22] are reported. The formation of BTZ solid solution is obtained by conventional sintering in the temperature range $1300-1450^{\circ} \mathrm{C}$ after $2-10 \mathrm{~h}$ treatment. In addition to conventional sintering, only few studies have also been conducted on BTZ ceramics using Spark Plasma Sintering (SPS) [2325]. The latter one is an efficient sintering process where powders are rapidly heated by Joule effect, due to the combination of pulsed electric current and the application of uniaxial mechanical pressure [26]. In particular, the structure and electromechanical properties of $\mathrm{Ba}\left(\mathrm{Zr}_{0.2} \mathrm{Ti}_{0.8}\right) \mathrm{O}_{3}$ ceramics obtained by SPS at $1100^{\circ} \mathrm{C}$ and subsequently annealed at $1000-1400^{\circ} \mathrm{C}$ for $12 \mathrm{~h}$ has been investigated by Maiwa [23, 27].

In this work, SHS and SPS techniques are combined for the first time for the preparation of $\mathrm{Zr}$-substituted barium titanate ceramics $\left(\mathrm{BaTi}_{(1-x)} \mathrm{Zr}_{x} \mathrm{O}_{3}\right)$. Briefly, SHS is a combustion synthesis method based on the local ignition of highly exothermic reactions which can self-propagate without additional energy supply [28-29]. Temperatures in the range 2000-5000 K and cooling rates up to $10^{3} \mathrm{~K} / \mathrm{min}$ can be reached during SHS and, more importantly, high-purity products can be correspondingly obtained in a very short time (order of seconds) [28].

The present work is aimed to produce single-phase $\mathrm{BaTi}_{(1-x)} \mathrm{Zr}_{x} \mathrm{O}_{3}(x=0.05-0.25)$ ceramics by combining the two fast processes mentioned above, i.e. by following the so-called SHS-SPS approach. The influence of the sintering temperature $\left(T_{D}\right)$ on density, composition (structure), dielectric, and piezoelectric properties of SHS-SPS ceramics is systematically investigated. The 
optimal SPS, as well as post-annealing, conditions, are then identified. A novel procedure of tuning the dielectric response of the BTZ ceramics by varying the sintering temperature, regardless of the $\mathrm{Zr}$ content, is presented.

\section{Experimental}

BTZ powders were prepared by SHS according to the following chemical equation:

$$
2 \mathrm{BaO}_{2}+(1-2 x) \mathrm{TiO}_{2}+2 x \mathrm{ZrO}_{2}+\mathrm{Ti} \rightarrow 2 \mathrm{BaTi}_{(1-x)} \mathrm{Zr}_{x} \mathrm{O}_{3}
$$

Hereto after, the $\mathrm{BaZr}_{0.05} \mathrm{Ti}_{0.95} \mathrm{O}_{3}, \mathrm{BaZr}_{0.10} \mathrm{Ti}_{0.90} \mathrm{O}_{3}, \mathrm{BaZr}_{0.15} \mathrm{Ti}_{0.85} \mathrm{O}_{3}, \mathrm{BaZr}_{0.20} \mathrm{Ti}_{0.80} \mathrm{O}_{3}$, and $\mathrm{BaZr}_{0.25} \mathrm{Ti}_{0.75} \mathrm{O}_{3}$ compositions will be indicated as BTZ005, BTZ010, BTZ015, BTZ020, and BTZ025, respectively. Details on the synthesis of the precursors and procedure can be found in [30].

The SHS products were first converted into powders after 20 min ball milling treatment using a SPEX 8000 mixer mill (SPEX CertiPrep, Metuchen, NJ, USA). It is worth to mention that such a mild milling conditions (the ball to powder weight ratio was only equal to 2) are not expected to modify the grain size of SHS product and, in turn, affect the microstructure of the sintered ceramics.

Subsequently, $3 \mathrm{~g}$ of the resulting powders were consolidated by SPS (515S model, Fuji Electronic Industrial Co., Ltd., Kanagawa, Japan) under vacuum conditions (down to $20 \mathrm{~Pa}$ ) and sintering temperatures $\left(T_{D}\right)$ in the range $1200-1400{ }^{\circ} \mathrm{C}$ (heating rate of $100^{\circ} \mathrm{C} / \mathrm{min}$ and holding time of $5 \mathrm{~min}$ ) with a mechanical pressure of $40 \mathrm{MPa}$. Graphite die of $14.7 \mathrm{~mm}$ inner diameter, 30 $\mathrm{mm}$ height, and $30 \mathrm{~mm}$ outer diameter was used. SPS runs were carried out under temperaturecontrolled mode using an optical pyrometer (IR-AHS2, Chino, Tokyo, Japan) focused on the external surface of the die. After SPS, the bulk samples were polished on their top and bottom 
surfaces using progressively finer abrasive paper, to finally obtain $2 \mathrm{~mm}$ thick disks. The pellets were then post annealed for $3 \mathrm{~h}$ at $1200^{\circ} \mathrm{C}$ (Nabertherm, mod. N60/ER, Germany) in an oxygenrich atmosphere to re-oxidize the samples and remove the carbon contamination arising from the graphite tools.

The absolute density values of the bulk specimens were determined by the Archimedes' method using distilled water as immersion medium. The crystalline phases in both the SHS powders and the SPS specimens were identified using an X-ray diffractometer (PANalytical X'pert Pro diffractometer, Netherlands; operating at $40 \mathrm{kV}$ and $40 \mathrm{~mA}$, using the $\mathrm{X}^{\prime}$ Celerator detector) equipped with a Ni filtered $\mathrm{CuK} \alpha$ radiation $(\lambda=1.5405 \AA)$. The relative content of the different phases was determined taking advantage of a Rietveld analytical procedure [31].

Fracture surfaces of BTZ ceramics were examined by high resolution scanning electron microscopy (HRSEM) (mod. S4000, Hitachi, Tokyo, Japan) equipped with a UltraDry EDS Detector (Thermo Fisher Scientific, Waltham, MA, USA). Microstructural analysis (grain size, porosity) were conducted on SEM images using the open source software Image J (version 1.54a for Windows, 64 bit, National Institutes of Health, Bethesda, MD, USA).

The dielectric measurements were carried out after depositing by sputtering gold electrodes on both sides of the dense ceramics (Technics Hummer JR, USA). The LCR meter (Wayne Kerr 4300 , London) recorded the capacitance and imaginary permittivity $\left(\varepsilon_{\mathrm{i}}\right)$ values from which the data acquisition program estimated the dielectric permittivity and dielectric loss. Liquid nitrogen was used to decrease the set-up temperature to about $85 \mathrm{~K}$ and a furnace (Eurotherm 3508 , UK) raised the temperature to $450 \mathrm{~K}$ which was measured using a K-type thermocouple. For the sake of reproducibility, each experiment was repeated at least twice. 
Regarding the measurement of the piezoelectric properties, the samples were poled at a high voltage of about $2 \mathrm{kV}(10 \mathrm{kV} / \mathrm{cm})$ generated by a suitable supply (AET technologies, France) at $80^{\circ} \mathrm{C}$ under Nitrogen gas in a furnace (AET technologies, France). The applied field was kept during sample's cooling. The resonance $\left(f_{r}\right)$ and anti-resonance $\left(f_{a}\right)$ frequencies from which the electromechanical parameters were estimated, have been obtained using a network analyzer (Agilent technologies E5061B, USA).

\section{Results}

\subsection{SHS powders of $\mathrm{Zr}$ substituted $\mathrm{BaTiO}_{3}$}

The five BTZ compositions investigated in the present work all display a self-propagating character, i.e. the reaction occurred spontaneously after initiation without additional energy, regardless of the $\mathrm{Zr}$ content. The XRD patterns of the resulting SHS products, after being milled to powders, are shown in Fig. 1.

The hexagonal $\mathrm{BaTiO}_{3}$ phase is the only one (matched with the JCPDS card reference pattern mentioned in Fig. 1) detected by this analysis for $x=0.05$ and 0.10 . Also, some peaks identified as $c \mathrm{BaZrO}_{3}$ and $t \mathrm{BTZ}$ appear in the XRD patterns of SHS products obtained for larger $\mathrm{Zr}$ content $(\mathrm{x}>0.10)$. Moreover, their intensity, and in particular that one of the main peak corresponding to the cubic $\mathrm{BaZrO}_{3}$ phase, progressively increase as the $x$ value is augmented. It is important to note that in the powders synthesized by SHS, the desired single phase BTZ was not achieved (Fig. 1), rather an additional $\mathrm{BaZrO}_{3}$ phase was formed, which implies that at this stage $\mathrm{Zr}$ is yet to be fully substituted in the $\mathrm{B}$ site of the $\mathrm{BaTiO}_{3}$ lattice.

In this regard, it is interesting to compare the composition and structure of BTZ powders obtained by SHS (Fig. 1) with those ones reported in the literature for analogous products prepared 
by calcination [20, 32-33]. The compositional/structural characteristics of $\mathrm{BaTi}_{(1-x)} \mathrm{Zr}_{x} \mathrm{O}_{3}$ products synthesized by calcination are found to depend on the $\mathrm{x}$ value. For instance, a tetragonal perovskite phase was obtained by Badapanda et al. [33] for BTZ005 powders calcined at $1100^{\circ} \mathrm{C}$ for $4 \mathrm{~h}$ after 5h milling. On the other hand, BTZ015 powders calcinated for $4 \mathrm{~h}$ at $1200^{\circ} \mathrm{C}$ after milling the reactants for 5h, lead to a single-phase cubic perovskite structure [20]. Similarly, Rout et al. [32] obtained a perovskite cubic BTZ025 phase after $4 \mathrm{~h}$ calcination at $1350^{\circ} \mathrm{C}$ of powders subjected to repeated cycles of mixing and grinding.

The diverse outcomes resulting from the two synthesis methods can be motivated as follows. The formation of the metastable hexagonal phase, which is not detected in calcinated powders, could be explained by the peculiar characteristics (i.e. process rapidity, high temperatures, heating and, above all, cooling rates) of the SHS method, which evolves quite far from the equilibrium conditions. Therefore, metastable phases could be retained at room temperature. In addition, the intense milling treatments performed when considering the calcination method $[\mathbf{2 0 , 3 2 - 3 3}$ certainly promote diffusion phenomena involved in the synthesis process, so that the formation of single-phase products is favored.

As mentioned in the Experimental section, in the present work the SHS products are mildly ball milled just to generate powders to be processed by SPS. Nonetheless, the effect of a more intense milling treatment on SHS powder and the resulting bulk BZT products characteristics will be the subject of a research work currently in progress.

\subsection{Spark Plasma Sintering of SHS powders}

The powders synthesized by SHS were then processed by SPS (5 min, $40 \mathrm{MPa}$, $\left.100^{\circ} \mathrm{C} / \mathrm{min}\right)$. The influence of the sintering temperature on the composition can be observed from 
room temperature XRD results depicted in (Fig. 2). Specifically, the XRD patterns of the bulk samples for the five BTZ systems are compared in Fig. 2(a)-(b) for two selected sintering temperatures $1200^{\circ} \mathrm{C}$ and $1400^{\circ} \mathrm{C}$, respectively. It is important to note that XRD data for $\mathrm{Zr}$ substituted $\mathrm{BaTiO}_{3}$ powders sintered at $T_{D}=1300^{\circ} \mathrm{C}$ are very similar to those ones obtained at $1400^{\circ} \mathrm{C}$, hence they are not reported here.

The XRD patterns evidence that, regardless of the $\mathrm{Zr}$ content, the $h \mathrm{BaTiO}_{3}$ originally present in SHS powders undergoes a gradual structural (phase) transformation during SPS. Specifically, this effect is more pronounced as the dwell temperature is increased from 1200 to $1400^{\circ} \mathrm{C}$. Nonetheless, when considering the composition corresponding to $x=0.05$, the original hexagonal phase is still significantly present in the sintered ceramic. A direct indication of the phase transformation observed when $x$ increases is provided, for example, by the intensity of the $h \mathrm{BaTiO}_{3}$ peak which falls in the range $26^{\circ} \leq 2 \theta \leq 27^{\circ}$. Such peak decreases and tends to disappear, particularly when $T_{D}=1400^{\circ} \mathrm{C}$. XRD analysis also evidences that, when the sintering process is performed at $1400^{\circ} \mathrm{C}$, the intensity of the $c \mathrm{BaZrO}_{3}$ and the $h \mathrm{BaTiO}_{3}$ peaks are also markedly reduced with respect to the starting SHS powders (Fig. 1). It is thus possible to conclude that, depending on the $x$ value, the content of $t$ BTZ or the $c$ BTZ phases is enhanced (Fig. 2(b)) during SPS when the sintering temperature is high enough. This is confirmed by the shift in $2 \theta$ diffraction peak at about $31^{\circ}$ towards a lower angle (Fig. 2(c)). However, a residual presence of $c \mathrm{BaZrO}_{3}$ is still detected by XRD. In the literature, the tetragonal phase is generally reported for $x \leq 0.08$ [ 8 , 34] while the cubic and/or rhombohedral phases are found for $x \geq 0.10[18, \mathbf{2 0}, \mathbf{3 5}-\mathbf{3 6}]$. 


\subsection{Post-annealing of SPS samples}

From the results described in section 3.2, it is found that the bulk specimens obtained by SPS still contain undesired secondary phases, particularly $h \mathrm{BaTiO}_{3}$ and/or $c \mathrm{BaZrO}_{3}$, whatever the $\mathrm{Zr}$ content. The effect of a post-heat treatment in air, conducted for $3 \mathrm{~h}$ at $1200^{\circ} \mathrm{C}$, on the composition of the BTZ ceramics produced by SPS at $T_{D}=1200,1300$, and $1400^{\circ} \mathrm{C}$, was then investigated. The room temperature XRD patterns of the corresponding post-annealed samples are shown in Fig. 3(a)-3(b), for the compositions corresponding to $x=0.05$ and 0.25, i.e. the lowest and highest $\mathrm{Zr}$ content examined in this work.

Let us consider first the ceramics obtained with the lowest $\mathrm{Zr}$ content (Fig. 3(a)-3(b)). The post-annealing treatment appears to remove the $h \mathrm{BaTiO}_{3}$ phase initially present in SPS sintered products (Fig. 2(a)-2(b)). Also, $t$ BTZ is the major phase detected by XRD at room temperature in post-thermal treated SPS ceramics obtained at $T_{D}=1200$ and $1300^{\circ} \mathrm{C}$. In particular, the Rietveld analysis (see Supplementary Table S1) revealed that, after the post-annealing process, the sintered product obtained by SPS at $\mathrm{T}_{\mathrm{D}}=1200^{\circ} \mathrm{C}$ is mainly composed of the $\mathrm{P} 4 \mathrm{~mm}$ tetragonal phase (about 87 wt. \%) with a small amount of the cubic Pm-3m phase (approximately 13 wt.\%). As the sintering temperature was augmented to $1400^{\circ} \mathrm{C}$, the content of the cubic phase in the postannealed ceramic increased at the expenses of the tetragonal one. Nonetheless, based on the Rietveld analysis, the BTZ005 sample obtained for $\mathrm{T}_{\mathrm{D}}=1400^{\circ} \mathrm{C}$ still consists of a mixture of tetragonal P4mm (about 70 wt.\%) and Pm-3m (about 30 wt.\%) phases (see Supplementary Table S1). The phases' coexistence could arise from the segregation of $\mathrm{Zr}$ when high sintering temperature $\left(1400^{\circ} \mathrm{C}\right)$ is applied on heterogeneous starting powders. As a result, ceramics containing $\mathrm{Zr}$ rich (cubic) and $\mathrm{Zr}$ poor (tetragonal) phases could be obtained [37]. 
XRD data of post-annealed SPS samples corresponding to $x=0.25$ are shown in Fig. 3(c). Residual $\mathrm{BaZrO}_{3}$ is reduced during post heat treatment in air, to finally provide single-phase $c$ BTZ for ceramics processed by SPS at $T_{D}=1400^{\circ} \mathrm{C}$, as confirmed by the Rietveld analysis (see Supplementary Table S1). It should be noted that the compositional changes observed when considering $x=0.10,0.15$, and 0.20 , not reported here for the sake of brevity, fall within those ones described above in the case of $x=0.05$ and 0.25 .

Another effect observed after the post-annealing treatment is the color change of SPS samples. Indeed, as shown in Fig. 4a, the resulting disks are dark, after the sintering process.

Regarding the latter finding, it should be noted that the dark color in barium titanate- as well as other oxide-based ceramics is general observed when the related synthesis and/or sintering processes are conducted under reducing environments. In the present work, both the SHS and SPS routes were performed under such condition. As far as the SHS powders are concerned, it was recently shown that their dark color is due to the fact that the synthesized products are oxygen deficient [30]. In addition, a heat-treatment of these powders in air at increasing temperatures (up to $1200{ }^{\circ} \mathrm{C}$ ) was found to determine a gradual color change from the initial dark to light yellow [30]. The same motivation is also valid to justify the dark color of bulk BTZ samples obtained in this work by SPS, since the adopted reducing conditions (vacuum) likely lead to the formation of oxygen vacancy. Accordingly, in order to restore the expected BTZ stoichiometry and also make the obtained ceramics insulating, a post-annealing treatment in air was carried out. The latter process performed at various temperature/time conditions evidences that, at relatively lower temperatures $\left(800-1000^{\circ} \mathrm{C}\right)$, the samples exhibited several cracks on their surface, and the transformation from dark to white color was not obtained. In contrast, such drawback was avoided, or strongly limited, when the annealing process was conducted for $3 \mathrm{~h}$ at $1200^{\circ} \mathrm{C}$. The optical 
images of the various BTZ samples correspondingly obtained are shown in Fig. 4b. The annealing process induces a significant color change from dark to white-grey in all BTZ ceramics. Thus, a post-annealing at $1200^{\circ} \mathrm{C}$ for $3 \mathrm{~h}$ appears as the optimal condition to be adopted.

\subsection{Microstructural characterizations}

SEM images of the fracture surfaces of BTZ005 and BTZ025 ceramics obtained by SPS at $T_{D}=1200$ and $1400^{\circ}$ and annealed at $1200^{\circ} \mathrm{C}$ for $3 \mathrm{~h}$ are shown in Fig. 5(a)-5(d). The densities of post-annealed ceramics are reported in Fig. S1 (Suppl. material).

BTZ005 sintered at $1200^{\circ} \mathrm{C}$ exhibits an inhomogeneous microstructure with several dense zones made of grains with a melted aspect that make an accurate evaluation of the corresponding grain size difficult (Fig.5a). These areas are still present in ceramics sintered at $1400^{\circ} \mathrm{C}$, while the microstructure is globally more homogeneous with well-defined grains and grain boundaries (Fig.5b). The observed transgranular fracture mode reflects weak grain boundaries. As far as the more homogeneous region of the BTZ005 sample sintered at $1400^{\circ} \mathrm{C}$ is concerned, grain size estimated using Image $\mathbf{J}$ software $[\mathbf{3 8}]$ is in the range $2-4 \mu \mathrm{m}$, so that no exaggerated grain growth is observed despite the high sintering temperature. The microstructure of BTZ025 ceramics sintered at $1200^{\circ} \mathrm{C}$ is characterized by a significant level of porosity and the presence of cracks (Fig.5c). This agrees with the low value of density obtained (Fig. S1). Similar to BTZ005, when the sintering temperature is increased up to $1400^{\circ} \mathrm{C}$, the microstructure becomes denser, in good agreement with the values reported in Fig. S1. The fracture remains transgranular and equiaxed grains in the size range $1-3 \mu \mathrm{m}$ are observed. As previously mentioned for the BTZ005 product sintered at $1400^{\circ} \mathrm{C}$, the corresponding grain size values were also estimated by considering the more homogeneous BTZ025 sample region where grain boundaries can be clearly identified. 


\subsection{Dielectric study}

\subsubsection{Effect of sintering temperature on dielectric behavior}

The variation of the dielectric permittivity as a function of temperature for the BTZ ceramics sintered at different $T_{D}$ and post-annealed for $3 \mathrm{~h}$ at $1200^{\circ} \mathrm{C}$ are shown in Fig. 6.

For a fixed composition, both the permittivity values and the transition temperatures are affected by the sintering temperature. Higher $T_{D}$ leads to a decrease of the temperature corresponding to the maximum of permittivity value $\left(T_{m}\right)$ as well as an increase in permittivity levels, especially in the vicinity of the transition (Fig. 7; Table S2 (Suppl. Material)). In particular, it is worth noting that, for the composition corresponding to $x=0.05$, a sintering temperature increase from $1200^{\circ} \mathrm{C}$ to $1400^{\circ} \mathrm{C}$ also induces a change from a classical ferroelectric to a more diffuse phase transition. A decrease of the Curie Temperature and an increase of the Rhombohedral (R)-Orthorhombic (O) $[\mathrm{R}-\mathrm{O}]$ and Orthorhombic $(\mathrm{O})-$ Tetragonal $(\mathrm{T})[\mathrm{O}-\mathrm{T}]$ phase transitions were correspondingly observed. When the $\mathrm{Zr}$ content is increased, the transition temperature is decreased, as expected, and for ceramics sintered at temperatures higher than $1200^{\circ} \mathrm{C}$, the ferroelectric behavior changes from classical $(x=0.05)$ to a diffuse mode $(x>0.10)$. The dielectric study as a function of temperature (Fig. 6) confirms the diffuse (not relaxor) behavior of the BTZ ceramics obtained by SHS-SPS, due to the absence shift in $\mathrm{T}_{\mathrm{m}}$ as a function of frequency for $0.05 \leq \mathrm{x}<0.20$ (Fig. S2 (Suppl. Material)). Whatever the $\mathrm{Zr}$ content and the sintering temperature, the dielectric loss at 1 $\mathrm{kHz}$ remains stable and mostly lower than $8 \%$. The comparison of dielectric behavior with regards to $T_{D}$ for each $\mathrm{Zr}$ composition is shown in Fig. S3 (Suppl. Material). 
To investigate the behavior in the paraelectric region, the Curie constant, $C$, was estimated from the Curie-Weiss law:

$$
\varepsilon=\frac{C}{\left(T-T_{o}\right)} ;\left(\mathrm{T}>\mathrm{T}_{\mathrm{c}}\right)
$$

where $T_{c}$ is the Curie point (transition temperature).

The inverse of the dielectric permittivity $(1 / \varepsilon)$ plotted as a function of temperature was used to estimate the Curie-Weiss temperature $\left(T_{o}\right)$ and the Curie constant Fig. 8 and Table S3 (Suppl.

\section{Material).}

Regarding the investigated range of $\mathrm{Zr}$ content, the Curie constant decreases monotonically with an increase of the $x$ value for a given $T_{D}$. Also, the Curie-Weiss temperature was found to decrease with $T_{D}$ and $\mathrm{Zr}$ content.

The modified Curie-Weiss $(\mathrm{C}-\mathrm{W})$ plot can be used to describe the deviation from linearity due to the diffuse character of the transition. The modified Curie-Weiss equation is given by:

$$
\frac{1}{\varepsilon}-\frac{1}{\varepsilon_{m}}=\frac{\left(T-T_{m}\right)^{\gamma}}{C} ;\left(\mathrm{T}>\mathrm{T}_{\mathrm{m}}\right)
$$

where $\varepsilon$ is the real permittivity, $\varepsilon_{m}$ is the maximum dielectric constant, $T_{m}$ is the temperature at the maximum dielectric permittivity, $\gamma$ is the diffuseness coefficient. For normal ferroelectrics $\gamma=1$, while for relaxor $\gamma=2$.

The modified Curie-Weiss plots and the corresponding data are provided in Fig. S4 and Table S3 (Suppl. Material), respectively.

To illustrate the change of behavior from classical to diffuse one as a function of the $\mathrm{Zr}$ content, the variation of $T_{c}\left(T_{m}\right)$ and diffuseness coefficient are presented in Fig. 9 for ceramics sintered at $1400^{\circ} \mathrm{C}$. 


\subsection{Piezoelectric study}

In Fig. 10 the results of the piezoelectric study of BTZ are presented. The piezoelectric charge coefficient $\left(d_{31}\right)$ and the planar electromechanical coupling factor $\left(k_{p}\right)$ were significantly influenced by the SPS temperature $\left(T_{D}\right)$. All samples show good mechanical quality factor $\left(Q_{m}\right)$, consistent with the low dielectric loss (see Supplementary Table S4). A graph showing impedance as a function of frequency, from which resonance and antiresonance frequencies can be obtained, is reported in Fig S5 (Supp. Material) for the case of BTZ005 ceramics sintered at $1300^{\circ} \mathrm{C}$.

BTZ025 samples could not be poled due to high current leakage arising from their low density. Hence, no piezoelectric data were obtained for this system. The following equations were used to obtain the electromechanical parameters [41]:

$$
\begin{aligned}
& Q_{m}=\frac{1}{2 \pi f_{r} Z_{m} C}\left(\frac{f_{a}^{2}}{f_{a}^{2}-f_{r}^{2}}\right) \\
& k_{p} \approx \frac{f_{a}^{2}-f_{r}^{2}}{f_{a}}, \\
& k_{31}=\sqrt{\frac{\pi}{2} \frac{f_{a}}{f_{r}} \frac{\pi}{2} \frac{f_{a}}{f_{r}}-\tan \left(\frac{\pi}{2} \frac{f_{a}}{f_{r}}\right)}, \\
& s_{11}^{E}=\frac{1}{4 \rho f_{r}^{2} w^{2}}, \\
& d_{31}=k_{31} \sqrt{\varepsilon s_{11}^{E}},
\end{aligned}
$$

where, in addition to the parameters $\left(d_{31}, k_{p}\right.$, and $\left.Q_{m}\right)$ previously defined, $f_{r}, f_{a}, Z_{m}, C, k_{31},, s_{11}^{E}, \varepsilon$, $\rho$, and $w$ are resonance frequency, anti-resonance frequency, minimum impedance, Capacitance (in Farads), electromechanical coupling factor in the length extensional mode, elastic coefficient 
at constant electric field, dielectric permittivity at room temperature, density in $\mathrm{Kg} / \mathrm{m}^{3}$, and width of the ceramics, respectively. 


\section{Discussion}

\subsection{Structural analysis of BTZ ceramics: from SHS powders to SPS and post-annealed samples. Evolution of their composition}

The presence of the high-temperature stable $h \mathrm{BaTiO}_{3}$ phase in the SHS product with a small contribution of peaks attributed to $t$ BTZ is likely ascribed to the severe processing conditions (high temperature, heating, and cooling rates) inherent to the synthesis process as well as to the reducing environment (Argon gas) correspondingly adopted. The additional $c \mathrm{BaZrO}_{3}$ phase is also detected at $\mathrm{Zr}$ content $\geq 15 \mathrm{wt} . \%$, i.e. (BTZ015, BTZ020, and BTZ025), proving that a solid solution has not formed between the $\mathrm{BaTiO}_{3}$ and $\mathrm{BaZrO}_{3}$ phases, while a co-existence of the individual phases is obtained. When $x \leq 0.10$, no $\mathrm{BaZrO}_{3}$ phase was detected due to the low concentration of $\mathrm{Zr}$. It should be noted that the detailed quantitative analysis of the XRD pattern (Rietveld method) for the BTZ015 powder also evidenced the presence of a small amount of $c$ $\mathrm{BaTiO}_{3}$ along with traces of $\mathrm{Ba}_{2} \mathrm{TiO}_{4}[30]$. Nonetheless, due to the relatively low intensity of the corresponding peaks, these two phases cannot be unequivocally identified in the XRD patterns shown in Fig. 1, so that they are not considered in the present work.

After SPS, a decrease in the $h \mathrm{BaTiO}_{3}$ peak intensity is observed with respect to the starting SHS powders. Moreover, according to the $\mathrm{Zr}$ content, the $h \mathrm{BaTiO}_{3}$ phase is gradually transformed into $t \mathrm{BTZ}$ or $c \mathrm{BTZ}$, as the $T_{D}$ value is progressively increased. The formation of $c \mathrm{BTZ}$ phase is favored by higher $\mathrm{Zr}$ amounts and when the sintering temperature is set to $1400^{\circ} \mathrm{C}$ (Fig. 2b-2c). Twofold effects are noticeable for both the highest $\mathrm{Zr}$ content (i.e $x=0.25$ ) and sintering temperature (i.e. $T_{D}=1400^{\circ} \mathrm{C}$ ), respectively: the formation of the $c$ BTZ phase concomitant with the disappearance of $t$ BTZ. In parallel, the secondary $c \mathrm{BaZrO}_{3}$ phase (c BZ) decreases progressively as the sintering temperature is increased from 1200 to $1400^{\circ} \mathrm{C}$. The overall $\mathrm{XRD}$ 
study shows that the targeted $\mathrm{BaTi}_{(1-x)} \mathrm{Zr}_{x} \mathrm{O}_{3}$ solid solution can only be obtained by SHS-SPS under specific composition and temperature conditions. A high-temperature treatment of the SPS product is required to obtain the targeted single-phase BTZ.

The decisive role of the post-annealing treatment on the evolution of the phases present in SPS ceramics is emphasized here. Beyond its re-oxidizing role, post-annealing, when performed at sufficiently high temperature, allows for the elimination of the $h \mathrm{BaTiO}_{3}$ phase still present in some of the SPS ceramics. However, it should be noted that, during the post-annealing process, the hexagonal and tetragonal phases are partially or fully converted into the cubic one (Supplementary Table S1). This finding agrees with the work of Jha and Jha [42] focused on $\mathrm{BaZr}_{0.05} \mathrm{Ti}_{0.95} \mathrm{O}_{3}$ ceramics obtained by conventional technique, where the sintering process conducted at higher temperatures caused the tetragonal to cubic phase transformation. The formation of the $c$ BTZ phase for Zr content corresponding to $x=0.10-0.25$ is also consistent with similar results reported in the literature for BTZ ceramics obtained by conventional solid-state reactions [36].

Besides, from the secondary $c \mathrm{BaZrO}_{3}$ phase evolution, which depends on the thermal cycle, it is clear that the procedure to eliminate such unwanted secondary phase is to combine the SPS process $\left(\mathrm{T}_{\mathrm{D}}=1400^{\circ} \mathrm{C}\right)$ with a post-thermal treatment carried out at $1200^{\circ} \mathrm{C}$ or higher temperatures (Fig. 3).

In addition, whatever the $\mathrm{Zr}$ content, the post-annealing must be performed at least at $1200^{\circ} \mathrm{C}$ to efficiently re-oxidize the samples. It is worth noting that an annealing duration of $3 \mathrm{~h}$ is not only efficient enough, but also much shorter than the one reported in the literature [23, 27]. 


\subsection{Dielectric behavior: Effect of sintering temperature and composition}

For a fixed $\mathrm{Zr}$ content $(x=0.05)$, a normal ferroelectric behavior is observed. However, for $T_{D}=1400^{\circ} \mathrm{C}$, the Orthorhombic-Tetragonal $[\mathrm{O}-\mathrm{T}]$ phase transition becomes less marked compared with ceramics obtained at $T_{D} \leq 1300^{\circ} \mathrm{C}$, and a broad transition is observed at $T_{c}$. This effect can be correlated with the XRD analysis that shows a transition, albeit uncomplete, from $t$ BTZ to $c$ BTZ, when increasing the sintering temperature. Generally, all BTZ ceramics compositions sintered at $T_{D}=1200^{\circ} \mathrm{C}$, showed a normal ferroelectric behavior except for the $x=0.25$ composition. In the latter case, the very diffuse phase transition associated with low permittivity values is correlated with the low value of density obtained at $1200^{\circ} \mathrm{C}$. The microstructural investigation of BTZ025 sintered at $1200^{\circ} \mathrm{C}$ confirms a poorly densified ceramic and the presence of cracks. It is worth noting that no significant shift in $T_{O-T}$ and $T_{c}$ was observed from $x=0.05$ to $x=0.20$, thus demonstrating that a sintering temperature of $1200^{\circ} \mathrm{C}$ is not sufficient to induce the Zr-Ti substitution.

When sintering is performed at $1400^{\circ} \mathrm{C}$, a continuous decrease of $T_{c}$ is observed when the composition was varied from $x=0.10$ to $x=0.25$ and the transition becomes more and more diffuse. A relaxor behavior starts to be detected for $x=0.25$ ( $\Delta T m=8$ from $100 \mathrm{~Hz}$ to $500 \mathrm{kHz})$, for which $c$ BTZ is the only phase observed on the room temperature XRD pattern (Fig. 3(c)).

As a result, a change from classical to diffuse ferroelectric behavior in SHS-SPS ceramics can be induced by increasing not only the $\mathrm{Zr}$ content but also the sintering temperature at a fixed composition. Considering the microstructural analysis, such dielectric behavior is not correlated to the microstructure, while, as expected, depends rather on compositional effects at the atomic scale. 
High diffusivity parameter $(\gamma)$ was observed at low $\mathrm{Zr}$ content. The reason for this finding could be related to the coexistence of tetragonal and cubic phases seen in Fig. 3(b). However, at high $\mathrm{Zr}$ content, the obtained $\gamma$ parameter is in the range of the values reported in the literature, which generally depend on the adopted synthesis process [35, 43-44]. In addition, similar to the works by Mahesh et al. [20] and Cai et al. [45], higher sintering temperature induces diffuse transition and increases the $\gamma$ parameter (see Supplementary Table S3). The $T_{c}\left(T_{m}\right)$ values obtained for the various compositions are in good agreement with the literature for BTZ ceramics obtained by other methods [46-48].

\subsection{Piezoelectric study}

Both the composition and the sintering temperature have an impact on the piezoelectric performances. The piezoelectric charge coefficient decreases with increasing $x$ values (Fig. 10(a)), which confirms that high $\mathrm{Zr}$ content does not favor the obtainment of good piezoelectric properties. This result is effectively in agreement with the improved piezoelectric properties reported for BTZ ceramics with $x \leq 0.08$ [44, $\mathbf{4 6} \mathbf{4 7 , 4 9 ]}$. In addition, our study also evidenced that, when operating under optimal SPS temperature $\left(T_{D}\right)$ conditions to obtain higher values of the dielectric permittivity, the piezoelectric properties are correspondingly enhanced, which is in line with results reported in the literature for BTZ ceramics produced by alternative techniques [49-50]. When considering $\mathrm{BTZ} 005$, sintering at $1200^{\circ} \mathrm{C}$ results in moderate density values and poor quality of grain boundaries, that are not convenient for improving piezoelectric properties. On the other hand, BTZ005 sintered at $1300^{\circ} \mathrm{C}$ exhibits the optimal piezoelectric properties, which is in agreement with the literature [39-40, 51]. However, the obtained piezoelectric coefficient remains relatively low when compared to the state of the art $[\mathbf{2 3}, \mathbf{4 7}, \mathbf{5 1}]$. Improvements based on 
microstructure (density and grain size) and on the poling conditions would allow reaching better performances. 


\section{Conclusion}

BTZ ceramics have gained a high interest due to the possibility to tailor their ferroelectric properties through a proper composition control. Different BTZ ceramics are produced in this work using a novel approach based on the combination of the fast SHS and SPS processes, followed by an air-thermal treatment of relatively short duration $(3 \mathrm{~h})$, compared to the annealing time $(10 \mathrm{~h})$ typically considered in the literature. Here, the possibility of tuning the dielectric response (from classical to diffuse phase transition or relaxor) by varying, for a given composition, the sintering temperature, was clearly evidenced. In this regard, it should be noted that, to the best of our knowledge, no study was reported so far in the literature on the influence of the SPS temperature on the dielectric behavior of BTZ ceramics, regardless of the method used for powder synthesis.

Specifically, it was observed that the $T_{D}$ value and the $\mathrm{Zr}$ content significantly impact the structure, microstructure, dielectric, and piezoelectric properties of the SHS-SPS prepared ceramics. The $\mathrm{BaZrO}_{3}$ impurity phase formed during SHS, and still present after SPS, was eliminated thanks to the post-annealing treatment of the sintered ceramics. Increasing the sintering temperature above $1200^{\circ} \mathrm{C}$ leads to improved density, more homogeneous microstructure, as well as enhanced dielectric permittivity. The ceramic containing 5 at. $\%$ of $\mathrm{Zr}$ sintered at $T_{D}=1300^{\circ} \mathrm{C}$ showed the best piezoelectric properties. Better performances are expected if a single-phase ceramic is obtained after SPS and the microstructure of the final ceramics is suitably refined. Work is underway along this direction. 


\section{Acknowledgments}

One of the authors (B.N.E) performed her activity in the framework of the International PhD in Innovation Sciences and Technologies at the University of Cagliari and is also grateful for the ERASMUS Placedoc program for allowing mobility to France. The valuable contribution of Dr. S. Garroni and Dr. A. Iacomini (University of Sassari, Italy) for Rietveld's analysis and useful discussion is gratefully acknowledged. 


\section{References}

[1] J.Z. Jiang, F.W. Poulsen, S. Mørup, Structure and thermal stability of nanostructured iron doped zirconia prepared by high-energy ball milling. J. Mat. Res. 14(1999)1343-1352. https://doi.org/10.1557/JMR.1999.0183.

[2] R. Potong, R. Rianyoi, A. Chaipanich, Dielectric Properties of Lead-Free Composites from 0-3 Barium Zirconate Titanate-Portland Cement Composites. Ferro. Lett. Sec., 38(2011) 18-23. https://doi.org/10.1080/07315171.2011.570176.

[3] R. Saravanan, Titanate based ceramic dielectric material, first ed., Materials research forum, Millersville, USA, 2018, pp 10. https://doi.org/10.21741/9781945291555.

[4] U. Ahmadu, A. Muazu, S. Umar, Physical properties of porous pure and $\mathrm{Zr} / \mathrm{Sn}$-doped nanocrystalline $\mathrm{BaTiO}_{3}$ ceramics, in: U.M. Basheer Al-Naib (Ed.), Recent Advances. Porous Ceramics, IntechOpen Ltd, London, UK, 2018, pp. 147-170. https://doi.org/10.5772/intechopen.75500.

[5] B. Garbarz-Glos, K. Bormanis, D. Sitko, Effect of Zr Doping on the Electrical Properties of $\begin{array}{lll}\mathrm{BaTiO}_{3} & \text { Ceramics. } & \text { Ferro. }\end{array}$ https://doi.org/10.1080/00150193.2011.578508.

[6] T. Maiti, R. Guo, A.S. Bhalla, Evaluation of experimental resume of $\mathrm{BaZr}_{\mathrm{x}} \mathrm{Ti}_{1-\mathrm{x}} \mathrm{O}_{3}$ with perspective to ferroelectric relaxor family: An overview. Ferro., 425(2011)4-26. https://doi.org/10.1080/00150193.2011.644168.

[7] T. Maiti, R. Guo, A.S. Bhalla, Structure-Property Phase Diagram of $\mathrm{BaZr}_{\mathrm{x}} \mathrm{Ti}_{1-\mathrm{x}} \mathrm{O}_{3} \mathrm{System}_{\text {, J. }}$ Am. Ceram. Soc., 91(2008)1769-1780. https://doi.org/10.1111/j.1551-2916.2008.02442.x. 
[8] N. Nanakorn, P. Jalupoom, N. Vaneesorn, A. Thanaboonsombut, Dielectric and ferroelectric properties of $\mathrm{Ba}\left(\mathrm{Zr}_{x} \mathrm{Ti}_{1-x}\right) \mathrm{O}_{3}$ ceramics. Ceram. Int., 34(2008)779-782. https://doi.org/10.1016/j.ceramint.2007.09.024.

[9] S.J. Kuang, X.G. Tang, L.Y. Li, Y.P. Jiang, Q.X. Liu, Influence of Zr dopant on the dielectric properties and Curie temperatures of $\mathrm{Ba}\left(\mathrm{Zr}_{x} \mathrm{Ti}_{1-x}\right) \mathrm{O}_{3}(0 \leq x \leq 0.12)$ ceramics. Scrip. Mat. 61(2009)68-71. https://doi.org/10.1016/j.scriptamat.2009.03.016.

[10] T. Maiti, R. Guo, R., A. S. Bhalla, 2007. Enhanced electric field tunable dielectric properties of $\mathrm{BaZr}_{\mathrm{x}} \mathrm{Ti}_{1-\mathrm{x}} \mathrm{O}_{3}$ relaxor ferroelectrics. Appl. Phys. Lett. 90, 182901. https://doi.org/10.1063/1.2734922.

[11] P.S. Dobal, A. Dixit, R.S. Katiyara, Z. Yu, R. Guo, A.S. Bhalla, Micro-Raman scattering and dielectric investigations of phase transition behavior in the $\mathrm{BaTiO}_{3}-\mathrm{BaZrO}_{3} \quad$ system. $\quad$ J. Appl. Phys. 89(2001)8085-8091. https://doi.org/10.1063/1.1369399.

[12] D. Hennings, A. Schnell, G. Simon, Diffuse Ferroelectric Phase Transitions in Ba(Til-y $\left.\mathrm{Zr}_{\mathrm{y}}\right)_{\mathrm{O}}$ Ceramics. J. Am. Ceram Soc., 65(1982) 539-544. https://doi.org/10.1111/j.11512916.1982.tb10778.x.

[13] J. Ravez, A. Simon, Temperature and Frequency Dielectric Response of Ferroelectric Ceramics with Composition $\mathrm{Ba}\left(\mathrm{Ti}_{1-\mathrm{x}} \mathrm{Zr}_{\mathrm{x}}\right) \mathrm{O}_{3}$. Eur. J. Sol. Inorg Chem. 34(1997), 1199-1209.

[14] M.H. Frey D.A. Payne, Grain-size effect on structure and phase transformations for barium titanate. Phys. Rev. B 54 (1996) 3158-3168. https://doi.org/10.1103/PhysRevB.54.3158.

[15] T.T. Fang, H.-L. Hsieh, F.-S. Shiau, Effects of Pore Morphology and Grain Size on the Dielectric Properties and Tetragonal-Cubic Phase Transition of High-Purity Barium 
Titanate. J. Am. Ceram Soc., 76(1993)1205-1211. https://doi.org/10.1111/j.11512916.1993.tb03742.x.

[16] X.G. Tang, J. Wang, X.X. Wang, H.L.W. Chan, Effects of grain size on the dielectric properties and tunabilities of sol-gel derived $\mathrm{Ba}\left(\mathrm{Zr}_{0.2} \mathrm{Ti}_{0.8}\right) \mathrm{O}_{3}$ ceramics. Sol. Comm. 131 (2004)163-168. https://doi.org/10.1016/j.ssc.2004.05.016.

[17] M. Aghayan, A.K. Zak, M. Behdani, A.M. Hashim, Sol-gel combustion synthesis of Zrdoped $\mathrm{BaTiO}_{3}$ nanopowders and ceramics: dielectric and ferroelectric studies, Ceram. Int. 40 (2014)16141-16146. https://doi.org/10.1016/j.ceramint.2014.07.045.

[18] M. Deluca, C.A. Vasilescu, A.C. Ianculescu, D.C. Berger, C.E. Ciomaga, L.P. Curecheriu, L. Stoleriu, A. Gajovic, L. Mitoseriu, C. Galassi, Investigation of the composition-dependent properties of $\mathrm{BaTi}_{1-x} \mathrm{Zr}_{x} \mathrm{O}_{3}$ ceramics prepared by the modified Pechini method, J. Eur. Ceram. Soc. 32(2012)3551-3566. http://dx.doi.org/10.1016/j.jeurceramsoc.2012.05.007.

[19] T. Badapanda, S. Chaterjee, A. Mishra, R. Ranjan, S. Anward, Electric field induced strain, switching and energy storage behaviour of lead free barium zirconium titanate ceramic, Phys. B 521(2017)264-269. https://doi.org/10.1016/j.physb.2017.07.013.

[20] M.L.V. Mahesh, V.V.B. Prasad, A.R. James, Effect of sintering temperature on the microstructure and electrical properties of zirconium doped barium titanate ceramics, $J$ Mat. Sci: Mat. Electron 24(2013)4684-4692. https://doi.org/10.1007/s10854-013-1460-3.

[21] P. Julphunthong, T. Bongkarn, Phase formation, microstructure and dielectric properties of $\mathrm{Ba}\left(\mathrm{Zr}_{0.1} \mathrm{Ti}_{0.9}\right) \mathrm{O}_{3}$ ceramics prepared via the combustion technique. Cur. Appl. Phys. 11 (2011)S60-S65.

[22] A. Ahmad, K.A. Razak, 2017. Synthesis of $\mathrm{BaTiO}_{3}$ and $\mathrm{Ba}\left(\mathrm{Zr}_{x} \mathrm{Ti}_{1-\mathrm{x}}\right) \mathrm{O}_{3}$ by using the soft combustion method. AIP Conf. Proc. 1865, 060001. https://doi.org/doi: 10.1063/1.4993377. 
[23] H. Maiwa, Electromechanical properties of $\mathrm{Ba}\left(\mathrm{Zr}_{0.2} \mathrm{Ti}_{0.8}\right) \mathrm{O}_{3}$ ceramics prepared by spark plasma sintering. $\quad$ Ceram. Int https://doi.org/10.1016/j.ceramint.2011.04.087.

[24] G. Philippot, M. Albino, U.-C. Chung, M. Josse, C. Elissalde, M. Maglione, C. Aymonier, Continuous $\mathrm{BaTi}_{1-\mathrm{y}} \mathrm{Zr}_{\mathrm{y}} \mathrm{O}_{3}(0 \leq \mathrm{y} \leq 1)$ nanocrystals synthesis in supercritical fluids for nanostructured lead-free ferroelectric ceramics. Mat. Des. 86(2015)354-360. https://doi.org/10.1016/j.matdes.2015.07.111.

[25] B. Liu, Y. Wu, Y.H. Huang, K. X. Song, Y.J. Wu, Enhanced dielectric strength and energy storage density in $\mathrm{BaTi}_{0.7} \mathrm{Zr}_{0.3} \mathrm{O}_{3}$ ceramics via spark plasma sintering, J Mater Sci. 54(2019)4511-4517. https://doi.org/10.1007/s10853-018-3170-y.

[26] R. Orrù, R. Licheri, A.M. Locci, A. Cincotti, G. Cao, Consolidation/synthesis of materials by electric current activated/assisted sintering. Mater. Sci. Eng. R 63(2009)127-287. https://doi.org/10.1016/j.mser.2008.09.003.

[27] H. Maiwa, Dielectric and Electromechanical Properties of $\mathrm{Ba}\left(\mathrm{Zr}_{x} \operatorname{Ti}_{1-x}\right) \mathrm{O}_{3}(x=0.1$ and 0.2) Ceramics Prepared by Spark Plasma Sintering, Jap. J. Appl. Phys.46(2007)7013-7017. https://doi.org/10.1143/JJAP.46.7013.

[28] A. Varma, A.S. Rogachev, A.S. Mukasyan, S. Hwang, Combustion Synthesis of Advanced Materials: Principles and Applications. Adv. Chem. Eng. 24(1998)79-226. https://doi.org/10.1016/S0065-2377(08)60093-9.

[29] A. Cincotti, R. Licheri, A.M. Locci, R. Orrù, G. Cao, A review on combustion synthesis of novel materials: Recent experimental and modeling results. J. Chem. Tech. Biot. 78(2003)122-127. https://doi.org/10.1002/jctb.757. 
[30] B.N. Ezealigo, R. Orrù, F. Torre, P.C. Ricci, F. Delogu, G. Cao, Annealing effects on the structural and optical properties of undoped and $\mathrm{Zr}$-doped $\mathrm{Ba}$ titanate prepared by selfpropagating high-temperature synthesis. Ceram. Int. 46(11) (2020) 17307-17314. https://doi.org/10.1016/j.ceramint.2020.04.019.

[31] L. Lutterotti, R. Ceccato, R. Dal Maschio, F. Pagani, Quantitative analysis of silicate glass in ceramic materials by the Rietveld method. Mater Sci Forum. 278-281 (1998) 87 https://doi.org/10.4028/www.scientific.net/MSF.278-281.87.

[32] S.K. Rout, L.S. Cavalcante, J.C. Sczancoski, T. Badapanda, S. Panigrahi, M.S. Li, Photoluminescence property of $\mathrm{Ba}\left(\mathrm{Zr}_{0.25} \mathrm{Ti}_{0.75}\right) \mathrm{O}_{3}$ powders prepared by solid state reaction and polymeric precursor method, Phys. B: Condens. Matter, 404(2009)3341-3347. https://doi.org/10.1016/j.physb.2009.05.014.

[33] T. Badapanda, S. Sarangi, B. Behera, P.K. Sahoo, S. Anwar, T.P. Sinha, G.E. Luz Jr., E. Longo, L.S. Cavalcante, Structural refinement, optical and ferroelectric properties of microcrystalline $\mathrm{Ba}\left(\mathrm{Zr}_{0.05} \mathrm{Ti}_{0.95}\right) \mathrm{O}_{3}$ perovskite. Curr. Appl. Phys., 14(2014)708715.https://doi.org/10.1016/j.cap.2014.02.015.

[34] N. Sawangwan, J. Barrel, K. Mackenzie, T. Tunkasiri, The Effect of Zr Content on Electrical Properties of $\mathrm{Ba}\left(\mathrm{Ti}_{1-\mathrm{X}} \mathrm{Zr}_{\mathrm{x}}\right) \mathrm{O}_{3}$ Ceramics. Appl. Phys. A 90(2008)723-727. https://doi.org/10.1007/s00339-007-4342-9.

[35] S. Mahajan, O.P. Thakur, C. Prakash, K. Sreenivas, Effect of Zr on dielectric, ferroelectric and impedance properties of $\mathrm{BaTiO}_{3}$ ceramic. Bull Mat. Sci., 34(2011)1483-1489. https://doi.org/10.1007/s12034-011-0347-2. 
[36] P. Sateesh, J. Omprakash, G.S. Kumar, G. S., G. Prasad, 2015. Studies of phase transition and impedance behavior of $\mathrm{Ba}(\mathrm{Zr}, \mathrm{Ti}) \mathrm{O}_{3}$ ceramics, J. Adv. Dielectrics, 5, 1550002. https://doi.org/ 10.1142/S2010135X15500022.

[37] F. Benaballah, A. Simon, H. Khemakhem, C. Elissalde, M. Maglione, 2011. Linking large piezoelectric coefficients to highly flexible polarization of lead free $\mathrm{BaTiO}_{3}-\mathrm{CaTiO}_{3}-\mathrm{BaZrO}_{3}$ ceramics. J. Appl. Phys. 109, 124116. https://doi.org/10.1063/1.3599854.

[38] C.A. Schneider, W.S Rasband, K.W. Eliceiri, NIH Image to Image J: 25 years of image analysis. Nat. methods 9(7) (2012)671-675. https://doi.org/doi: 10.1038/nmeth.2089.

[39] Z. Yu, C. Ang, R. Guo, A.S. Bhalla, Piezoelectric and strain properties of $\mathrm{Ba}\left(\mathrm{Ti}_{1-x} \mathrm{Zr}_{\mathrm{x}}\right) \mathrm{O}_{3}$ ceramics. J. Appl. Phys. 92(2002)1489-1493. https://doi.org/10.1063/1.1487435.

[40] P. Zheng, J.L. Zhang, S.F. Shao, Y.Q. Tan, C.L. Wang, Piezoelectric properties and stabilities of CuO-modified ceramics. Appl. Phys. Lett. 94(2009)032902. https://doi.org/10.1063/1.3072347.

[41] T.L. Jordan and Z. Ounaies, Piezoelectric Ceramics Characterization, NASA, Langley $\begin{array}{llll}\text { Research } & \text { Center } & \text { Hampton, }\end{array}$ https://apps.dtic.mil/dtic/tr/fulltext/u2/a395517.pdf

[42] P.A. Jha, A.K. Jha, Effect of sintering temperature on the grain growth and electrical properties of barium zirconate titanate ferroelectric ceramics. J Mat. Sci: Mat. Electron 24(2013)1511-1518. https://doi.org/10.1007/s10854-012-0963-7.

[43] Z. Sun, Y. Pun, Z. Dong, Y. Hu, X. Liu, P. Wang, Effect of $\mathrm{Zr}^{4+}$ content on the $\mathrm{T}_{\mathrm{C}}$ range and dielectric and ferroelectric properties of $\mathrm{BaZr}_{\mathrm{x}} \mathrm{Ti}_{1-\mathrm{x}} \mathrm{O}_{3}$ ceramics prepared by microwave $\begin{array}{lllll}\text { sintering. } & \text { Ceram. } & \text { Int. } & 40 \quad \text { 3589-3594, }\end{array}$ http://dx.doi.org/10.1016/j.ceramint.2013.09.069. 
[44] C. Fu, F. Pan, W. Cai, X. Deng, X. Liu, 2009. Microstructures and dielectric properties of $\mathrm{BaZr}_{0.2} \mathrm{Ti}_{0.8} \mathrm{O}_{3}$ ceramics. J Phys. Conf. Ser. 152, 012075. https://doi.org/10.1088/1742$6596 / 152 / 1 / 012075$.

[45] W. Cai, J. Gao, M. Zhang, C. Fu, Effect of sintering temperature on diffuse phase transition of barium zirconate titanate ceramics. Int. Ferro. 105 (2009) 1-10. https://doi.org/10.1080/10584580903034548.

[46] Z. Yu, R. Guo, A.S. Bhalla, Dielectric behavior of $\mathrm{Ba}\left(\mathrm{Ti}_{1-x} \mathrm{Zr}_{x}\right) \mathrm{O}_{3}$ single crystals, J. Appl. Phys. 88 (2000)410-415. https://doi.org/10.1063/1.373674.

[47] L. Dong, D.S. Stone, R.S. Lakes, Enhanced dielectric and piezoelectric properties of $\mathrm{xBaZrO}_{3}-(1-\mathrm{x}) \mathrm{BaTiO}_{3} \quad$ ceramics, 2012. J Appl. Phys. 111, 084107 http://dx.doi.org/10.1063/1.4705467.

[48] F. Moura, A.Z. Simões, B.D. Stojanovic, M.A. Zaghete, E. Longo, J.A. Varela, Dielectric and ferroelectric characteristics of barium zirconate titanate ceramics prepared from mixed oxide method, J. Alloys and Compds 462(2008)129-134. http://dx.doi.org/10.1016/j.jallcom.2007.07.077.

[49] A.K. Kalyani, K. Brajesh, A. Senyshyn, R. Ranjan, 2014. Orthorhombic-tetragonal phase coexistence and enhanced piezo-response at room temperature in $\mathrm{Zr}$, Sn, and Hf modified $\mathrm{BaTiO}_{3}$. Appl. Phys. Lett. 104, 252906. https://doi.org/10.1063/1.4885516.

[50] S.-J. Jeong, D.-S. Lee, E.-C. Park, J.-S. Song, Piezoelectric properties of a $\mathrm{Ba}\left(\mathrm{Zr}_{0.075} \mathrm{Ti}_{0.925}\right) \mathrm{O}_{3}$ single crystal induced by poling treatment. J Electroceram, 17(2006)537-541. https://doi.org/10.1007/s10832-006-7724-z. 
[51] W. Li, Z. Xu, R. Chu, P. Fu, G. Zang, Dielectric and piezoelectric properties of $\mathrm{Ba}\left(\mathrm{Zr}_{\mathrm{x}} \mathrm{Ti}_{1-}\right.$ х) $\mathrm{O}_{3}$ lead-free ceramics. Braz. J. Phys. 40(2010)353-356. http://dx.doi.org/10.1590/S010397332010000300018. 


\section{Figures}

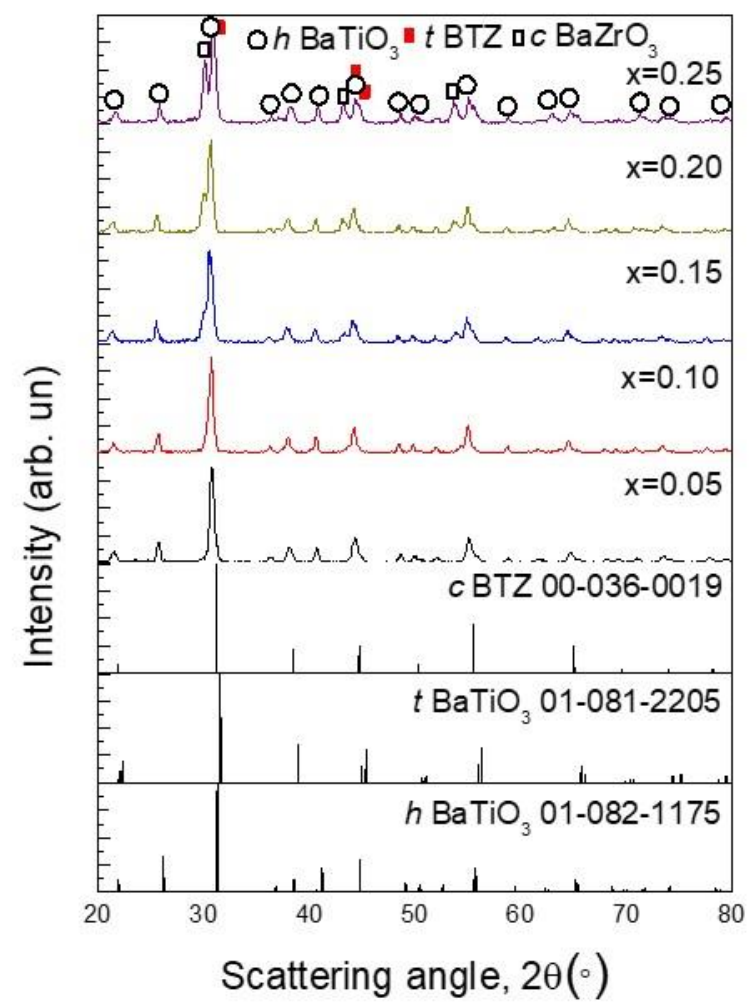

Figure 1: Room temperature XRD patterns of powders obtained by SHS for different $x$ values (cf.

Eq. 1). 

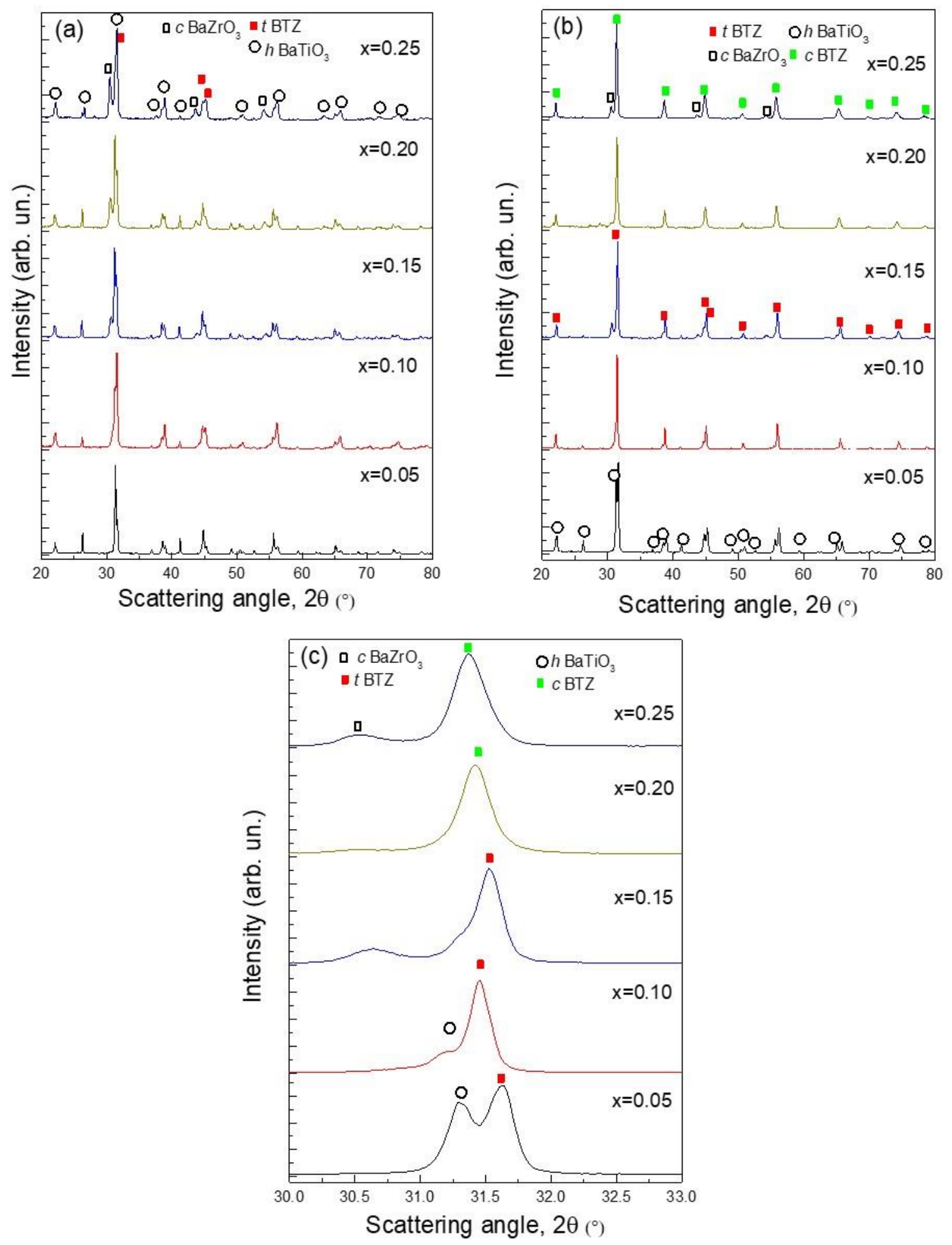

Figure 2: XRD patterns of BTZ ceramics obtained by SPS at (a) $T_{D}=1200^{\circ} \mathrm{C}$, (b) $T_{D}=1400^{\circ} \mathrm{C}$, (c) Zoomed view of (b). 

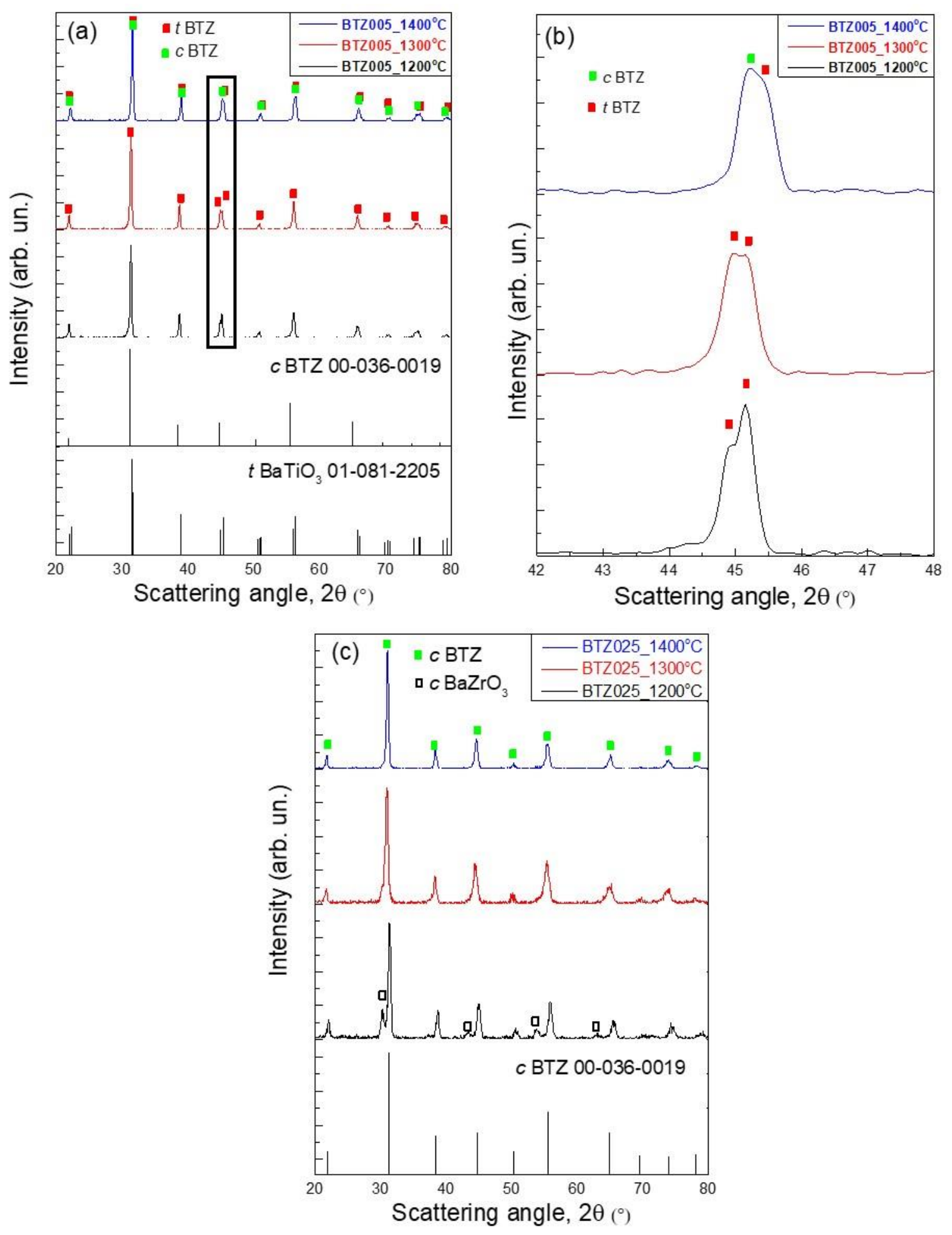

Figure 3: XRD patterns of (a)-(b) BTZ005, and (c) BTZ025 ceramics obtained by SPS ( $T_{D}=1200$, 1300 , and $1400^{\circ} \mathrm{C}$ ) after being post annealed for $3 \mathrm{~h}$ at $1200^{\circ} \mathrm{C}$. 
(a)

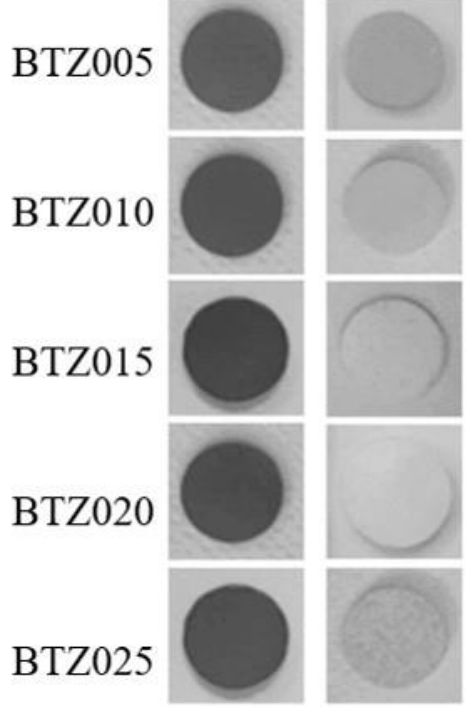

Figure 4: Images of $\mathrm{BaTi}_{(1-x)} \mathrm{Zr}_{x} \mathrm{O}_{3}(x=0.05-0.25)$ ceramics sintered by SPS at $1400^{\circ} \mathrm{C}$ before (a) and after (b) post-annealing at $1200^{\circ} \mathrm{C}$ for $3 \mathrm{~h}$. 

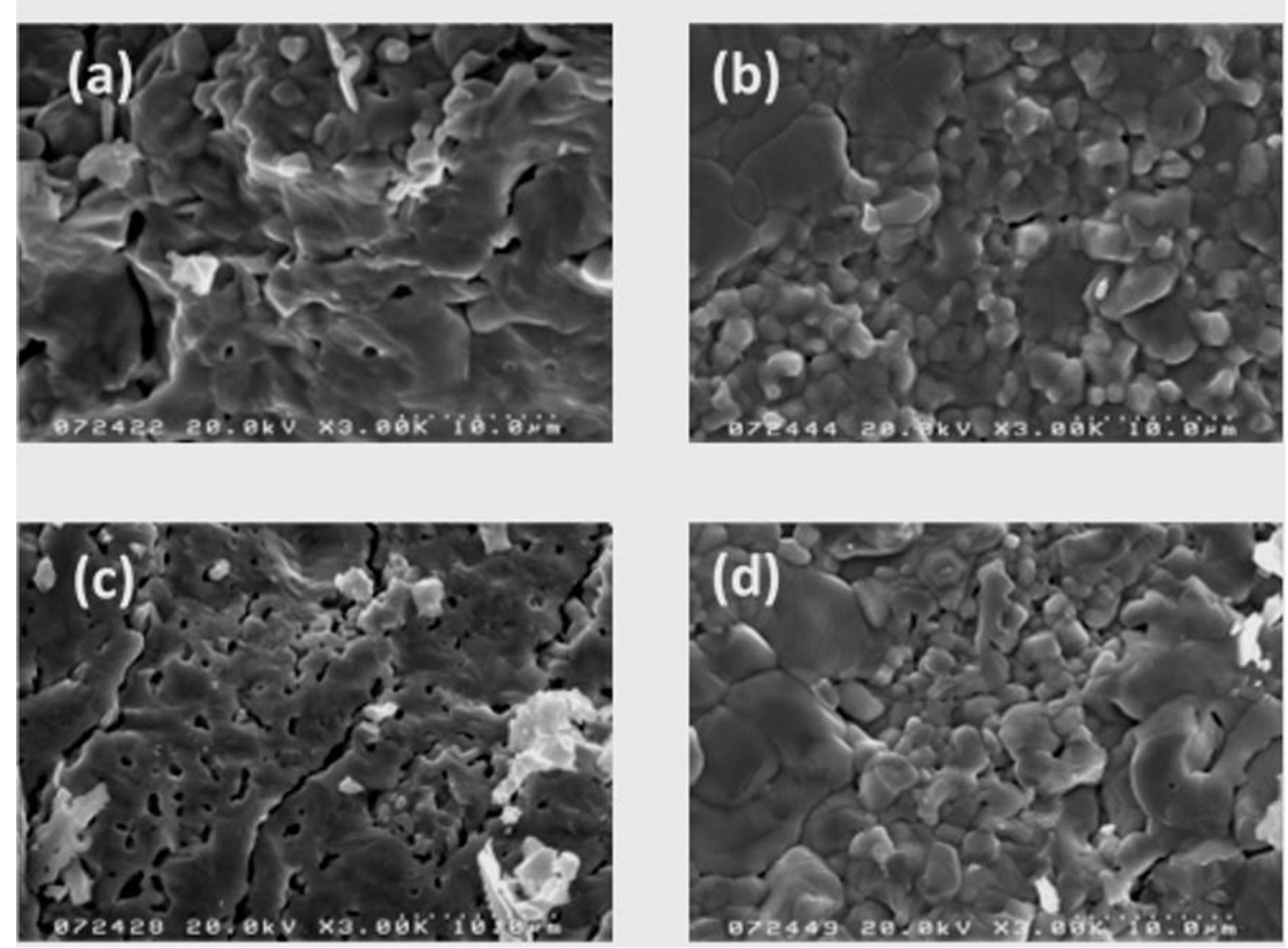

Figure 5: Fractured surfaces of BTZ ceramics obtained by SPS and subsequently annealed at $1200^{\circ} \mathrm{C}$ for $3 \mathrm{~h}$ : (a) BTZ005, $T_{D}=1200^{\circ} \mathrm{C}$; (b) BTZ005, $T_{D}=1400^{\circ} \mathrm{C}$; (c) BTZ025, $T_{D}=1200^{\circ} \mathrm{C}$; (d) $\mathrm{BTZ} 025, T_{D}=1400^{\circ} \mathrm{C}$. 

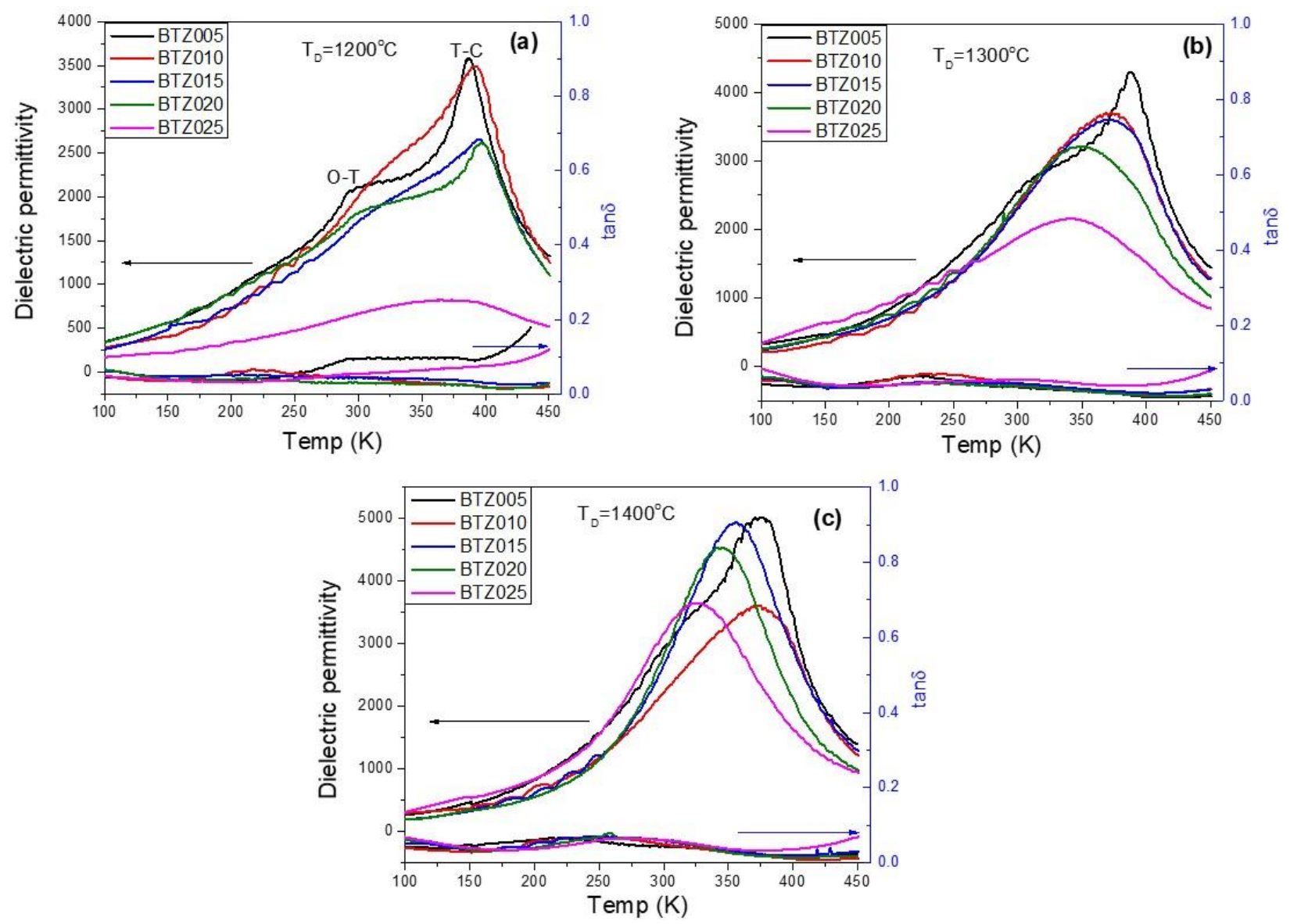

Figure 6: Dielectric permittivity and loss $(1 \mathrm{kHz})$ of $\mathrm{BaTi}_{(1-x)} \mathrm{Zr}_{x} \mathrm{O}_{3}(x=0.05-0.25)$ ceramics: (a) $T_{D}=1200^{\circ} \mathrm{C}$, (b) $T_{D}=1300^{\circ} \mathrm{C}$, and (c) $T_{D}=1400^{\circ} \mathrm{C}$. All samples were post-annealed for $3 \mathrm{~h}$ at $1200^{\circ} \mathrm{C} .(\mathrm{O}=$ orthorhombic; $\mathrm{T}=$ tetragonal; $\mathrm{C}=$ cubic phase transition $)$ 

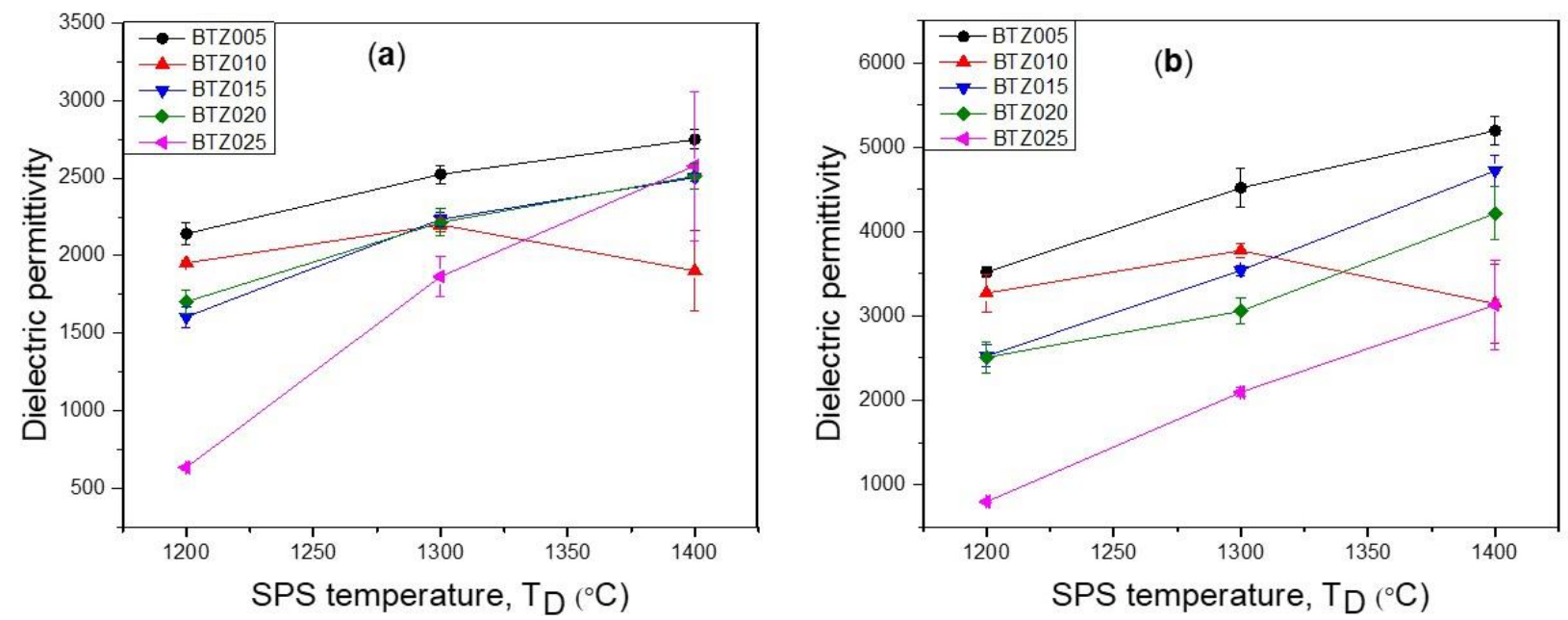

Figure 7: Dielectric permittivity at (a) room $\left(25^{\circ} \mathrm{C}\right)$ and (b) Curie $\left(\mathrm{T}_{\mathrm{c}}\right)$ temperature of $\operatorname{BaTi}_{(1-}$ ${ }_{x} \mathrm{Zr}_{x} \mathrm{O}_{3}(x=0.05-0.25)$ ceramics as a function of $\mathrm{T}_{\mathrm{D}}$. 

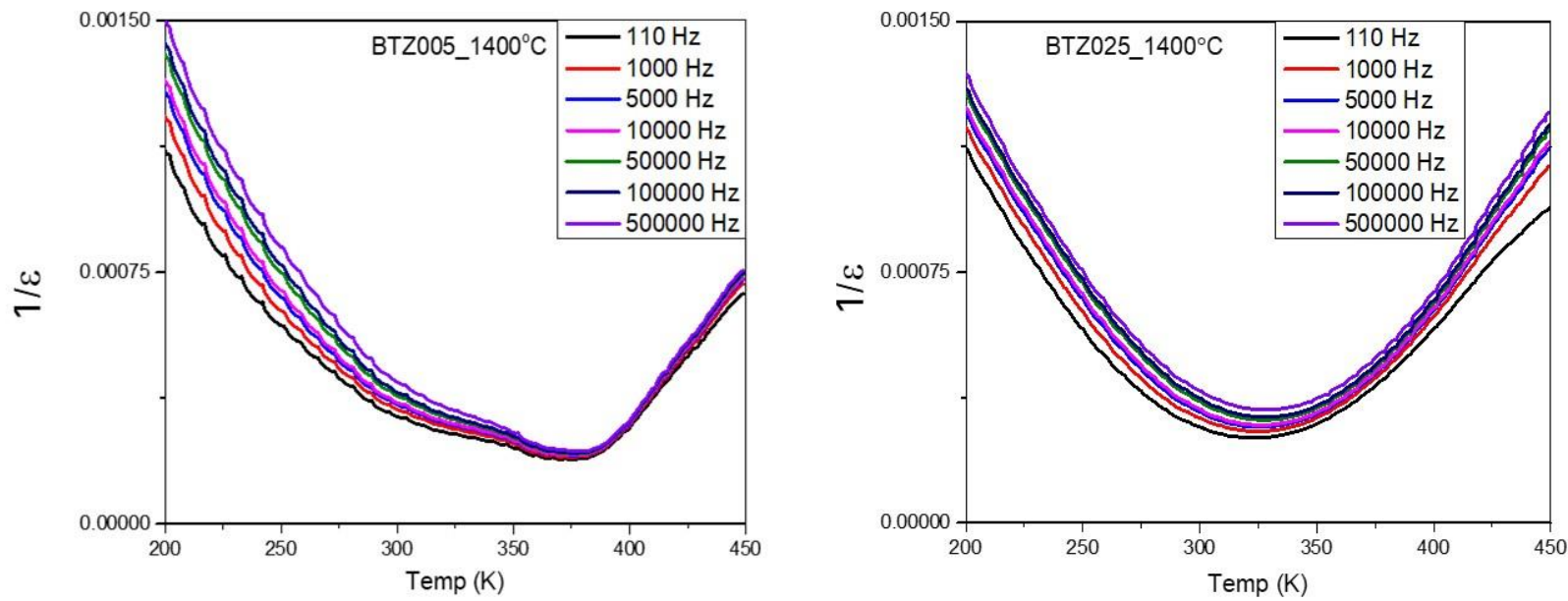

Figure 8: Curie-Weiss plots of $\mathrm{BaTi}_{(1-x)} \mathrm{Zr}_{x} \mathrm{O}_{3}(x=0.05$ and 0.25$)$ ceramics sintered at $1400^{\circ} \mathrm{C}$ and subsequently post-annealed at $1200^{\circ} \mathrm{C}$ for $3 \mathrm{~h}$. 


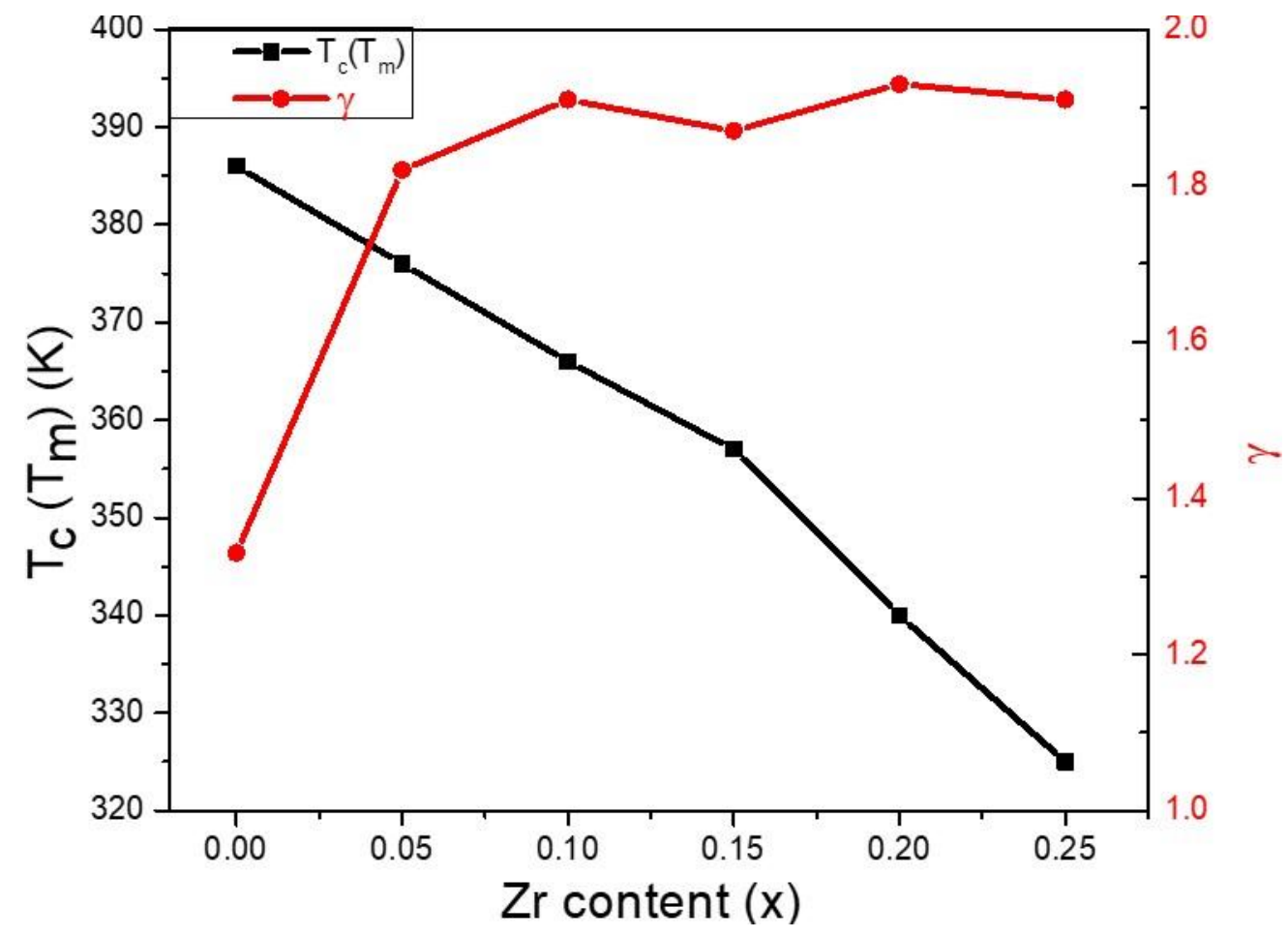

Figure 9: Plot of $T_{c}\left(T_{m}\right)$ at $1 \mathrm{kHz}$ and diffuseness coefficient $(\gamma)$ as a function of $\mathrm{Zr}$ content for ceramics sintered at $1400^{\circ} \mathrm{C}$ and subsequently post-annealed at $1200^{\circ} \mathrm{C}$ for $3 \mathrm{~h}$. 

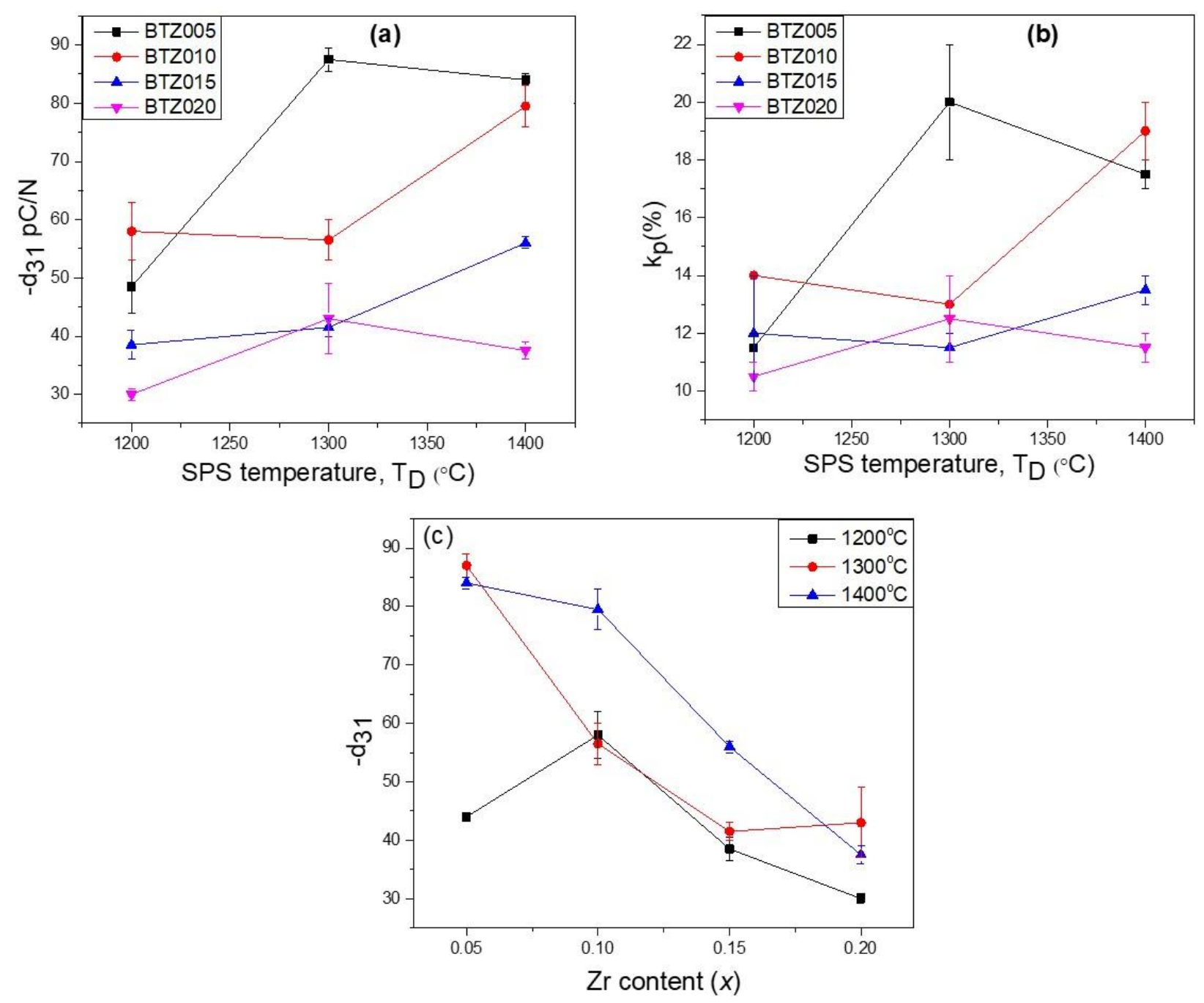

Figure 10: Piezoelectric properties of BTZ ceramics annealed at $1200^{\circ} \mathrm{C}$ for $3 \mathrm{~h}$. (a) Piezoelectric charge coefficient $\left(d_{31}\right)$ and (b) planar coupling factor $\left(k_{p}\right)$ as a function of sintering temperature; (c) piezoelectric charge coefficient $\left(d_{31}\right)$ as a function of $\mathrm{Zr}$ content. 


\section{Supplementary Material}

\section{Influence of the Spark Plasma Sintering temperature on the structure and dielectric properties of $\mathrm{BaTi}_{(1-\mathrm{x})} \mathrm{Zr}_{\mathrm{x}} \mathrm{O}_{3}$ ceramics}

Blessing N. Ezealigo ${ }^{1}$, Roberto Orrù ${ }^{1, *}$, Catherine Elissalde ${ }^{2, *}$, Hélène Debéda ${ }^{3}$, U-Chan Chung $^{2}$, Mario Maglione ${ }^{2}$, Giacomo Cao ${ }^{1}$

${ }^{1}$ Dipartimento di Ingegneria Meccanica, Chimica e dei Materiali, Unità di Ricerca del Consorzio Interuniversitario Nazionale per la Scienza e Tecnologia dei Materiali (INSTM) - Università degli Studi di Cagliari, via Marengo 2, 09123 Cagliari, Italy

${ }^{2}$ Université de Bordeaux, CNRS, ICMCB, UMR 5026, 87 avenue du Dr A. Schweitzer, 33608 Pessac, France

${ }^{3}$ Université de Bordeaux, Laboratoire IMS, UMR 5218, 351 Cours de la Libération, 33405 Talence, Cedex, France

Corresponding author: Roberto Orrù (roberto.orru@dimcm.unica.it); Catherine Elissalde (catherine.elissalde@icmcb.cnrs.fr)

Supplementary Tables S1-S4

Supplementary Figure S1-S5 
Table S1: Phases and quantitative phase analysis results (Rietveld procedure) of post annealed BTZ005 $\left(\mathrm{T}_{\mathrm{D}}=1200^{\circ} \mathrm{C}\right.$ and $\left.\mathrm{T}_{\mathrm{D}}=1400^{\circ} \mathrm{C}\right)$ and $\mathrm{BTZ} 025\left(\mathrm{~T}_{\mathrm{D}}=1400^{\circ} \mathrm{C}\right)$ samples.

\begin{tabular}{|c|c|c|c|}
\hline \multicolumn{4}{|c|}{$\operatorname{BTZ005}\left(\mathrm{T}_{\mathrm{D}}=1200^{\circ} \mathrm{C}\right)$} \\
\hline Phase & $\begin{array}{l}\mathbf{a} \\
(\AA)\end{array}$ & $\begin{array}{l}\text { c } \\
(\AA)\end{array}$ & $\begin{array}{l}\text { Wt. } \\
(\%)\end{array}$ \\
\hline Tetragonal P4mm $\left(\mathrm{BaTiO}_{3}\right)$ & 3.998 & 4.022 & 87.5 \\
\hline Cubic Pm-3m $\left(\mathrm{BaTiO}_{3}\right)$ & 4.056 & I & 12.5 \\
\hline \multicolumn{4}{|c|}{$\operatorname{BTZ005}\left(T_{D}=1400^{\circ} \mathrm{C}\right)$} \\
\hline Phase & $\begin{array}{l}\mathbf{a} \\
(\stackrel{\AA}{\mathrm{A}})\end{array}$ & $\begin{array}{l}\text { c } \\
(\stackrel{\AA}{\mathbf{A}})\end{array}$ & $\begin{array}{l}\text { Wt. } \\
(\%)\end{array}$ \\
\hline Tetragonal P4mm $\left(\mathrm{BaTiO}_{3}\right)$ & 3.995 & 4.024 & 70.3 \\
\hline Cubic Pm-3m $\left(\mathrm{BaTiO}_{3}\right)$ & 4.017 & l & 29.7 \\
\hline \multicolumn{4}{|c|}{$\operatorname{BTZ025}\left(T_{D}=1400^{\circ} \mathrm{C}\right)$} \\
\hline Phase & $\begin{array}{l}\mathbf{a} \\
(\mathbf{A})\end{array}$ & $\begin{array}{l}\text { c } \\
(\mathbf{A})\end{array}$ & $\begin{array}{l}\text { Wt. } \\
(\%)\end{array}$ \\
\hline Cubic Pm-3m $\left(\mathrm{BaTiO}_{3}\right)$ & 4.040 & l & 100 \\
\hline
\end{tabular}


Table S2: Dielectric characteristics at $1 \mathrm{kHz}$ of $\mathrm{BaZr}_{x} \mathrm{Ti}_{(1-x)} \mathrm{O}_{3}(x=0.05-0.25)$ ceramics. $\mathrm{T}_{\mathrm{D}}$ values are indicated below samples ID.

\begin{tabular}{|c|c|c|c|c|}
\hline $\begin{array}{l}\text { Sample } \\
\text { ID }\end{array}$ & $\begin{array}{l}\text { Dielectric } \\
\text { constant at room } \\
\text { temperature }\end{array}$ & $\begin{array}{l}\text { Dielectric } \\
\text { constant at Curie } \\
\text { temperature }\end{array}$ & $\begin{array}{l}\tan \delta \text { at } \\
\text { room } \\
\text { temperature }\end{array}$ & $\begin{array}{l}\tan \delta \text { at } \\
\text { Curie } \\
\text { temperature }\end{array}$ \\
\hline $\begin{array}{l}\text { BTZ005 } \\
1200^{\circ} \mathrm{C}\end{array}$ & $2142 \pm 73$ & $3521 \pm 56$ & 0.041 & 0.031 \\
\hline $\begin{array}{l}\text { BTZ005 } \\
1300^{\circ} \mathrm{C}\end{array}$ & $2524 \pm 57$ & $4518 \pm 228$ & 0.039 & 0.016 \\
\hline $\begin{array}{l}\text { BTZ005 } \\
1400^{\circ} \mathrm{C}\end{array}$ & $2749 \pm 63$ & $5195 \mathrm{~s} \pm 172$ & 0.044 & 0.020 \\
\hline $\begin{array}{l}\text { BTZ010 } \\
1200^{\circ} \mathrm{C}\end{array}$ & $1954 \pm 15$ & $3269 \pm 218$ & 0.044 & 0.021 \\
\hline $\begin{array}{l}\text { BTZ010 } \\
1300^{\circ} \mathrm{C}\end{array}$ & $2199 \pm 42$ & $3775 \pm 82$ & 0.048 & 0.024 \\
\hline $\begin{array}{l}\text { BTZ010 } \\
1400^{\circ} \mathrm{C}\end{array}$ & $1903 \pm 256$ & $3145 \pm 465$ & 0.053 & 0.015 \\
\hline $\begin{array}{l}\text { BTZ015 } \\
1200^{\circ} \mathrm{C}\end{array}$ & $1606 \pm 67$ & $2525 \pm 129$ & 0.043 & 0.023 \\
\hline $\begin{array}{l}\text { BTZ015 } \\
1300^{\circ} \mathrm{C}\end{array}$ & $2234 \pm 45$ & $3541 \pm 61$ & 0.046 & 0.027 \\
\hline $\begin{array}{l}\text { BTZ015 } \\
1400^{\circ} \mathrm{C}\end{array}$ & $2503 \pm 26$ & $4721 \pm 181$ & 0.059 & 0.030 \\
\hline $\begin{array}{l}\text { BTZ020 } \\
1200^{\circ} \mathrm{C}\end{array}$ & $1703 \pm 75$ & $2510 \pm 182$ & 0.031 & 0.020 \\
\hline $\begin{array}{l}\text { BTZ020 } \\
1300^{\circ} \mathrm{C}\end{array}$ & $2215 \pm 86$ & $3057 \pm 150$ & 0.039 & 0.028 \\
\hline $\begin{array}{l}\text { BTZ020 } \\
1400^{\circ} \mathrm{C}\end{array}$ & $2514 \pm 83$ & $4216 \pm 314$ & 0.058 & 0.032 \\
\hline $\begin{array}{l}\text { BTZ025 } \\
1200^{\circ} \mathrm{C}\end{array}$ & $635 \pm 17$ & $799 \pm 21$ & 0.067 & 0.078 \\
\hline $\begin{array}{l}\text { BTZ025 } \\
1300^{\circ} \mathrm{C}\end{array}$ & $1866 \pm 127$ & $2097 \pm 57$ & 0.055 & 0.048 \\
\hline $\begin{array}{l}\text { BTZ025 } \\
1400^{\circ} \mathrm{C}\end{array}$ & $2579 \pm 480$ & $3128 \pm 525$ & 0.063 & 0.052 \\
\hline
\end{tabular}


Table S3: Curie temperature, Curie-Weiss temperature, temperature of deviation from CurieWeiss law, Curie constant, and diffuseness coefficient values of $\mathrm{BaZr}_{x} \mathrm{Ti}_{(1-x)} \mathrm{O}_{3}$ ceramics. $\mathrm{T}_{\mathrm{D}}$ values are indicated below samples ID.

\begin{tabular}{|c|c|c|c|c|c|}
\hline $\begin{array}{l}\text { Sample } \\
\text { ID }\end{array}$ & $\mathbf{T}_{\mathrm{c}}\left(\mathbf{T}_{\mathbf{m}}\right)(\mathbf{K})$ & $\mathbf{T}_{0}(\mathbf{K})$ & $\mathbf{T}_{\mathrm{cw}}(\mathbf{K})$ & $\begin{array}{l}\text { Curie constant }\left(K^{-1}\right) \\
\times 10^{5}\end{array}$ & $\gamma$ \\
\hline $\begin{array}{l}\text { BTZ005 } \\
1200^{\circ} \mathrm{C}\end{array}$ & 386 & 361 & 399 & 1.22 & 1.42 \\
\hline $\begin{array}{l}\text { BTZ005 } \\
1300^{\circ} \mathrm{C}\end{array}$ & 386 & 370 & 401 & 1.39 & 1.69 \\
\hline $\begin{array}{l}\text { BTZ005 } \\
1400^{\circ} \mathrm{C}\end{array}$ & 378 & 368 & 401 & 1.23 & 1.82 \\
\hline $\begin{array}{l}\text { BTZ010 } \\
1200^{\circ} \mathrm{C}\end{array}$ & 390 & 373 & 408 & 1.02 & 1.71 \\
\hline $\begin{array}{l}\text { BTZ010 } \\
1300^{\circ} \mathrm{C}\end{array}$ & 369 & 362 & 403 & 1.31 & 1.83 \\
\hline $\begin{array}{l}\text { BTZ010 } \\
1400^{\circ} \mathrm{C}\end{array}$ & 366 & 360 & 403 & 1.11 & 1.85 \\
\hline $\begin{array}{l}\text { BTZ015 } \\
1200^{\circ} \mathrm{C}\end{array}$ & 393 & 367 & 415 & 0.98 & 1.81 \\
\hline $\begin{array}{l}\text { BTZ015 } \\
1300^{\circ} \mathrm{C}\end{array}$ & 370 & 374 & 410 & 1.12 & 1.86 \\
\hline $\begin{array}{l}\text { BTZ015 } \\
1400^{\circ} \mathrm{C}\end{array}$ & 350 & 361 & 402 & 1.30 & 1.83 \\
\hline $\begin{array}{l}\text { BTZ020 } \\
1200^{\circ} \mathrm{C}\end{array}$ & 396 & 371 & 417 & 0.97 & 1.66 \\
\hline $\begin{array}{l}\text { BTZ020 } \\
1300^{\circ} \mathrm{C}\end{array}$ & 347 & 360 & 406 & 0.94 & 1.86 \\
\hline $\begin{array}{l}\text { BTZ020 } \\
1400^{\circ} \mathrm{C}\end{array}$ & 341 & 356 & 397 & 1.14 & 1.9 \\
\hline $\begin{array}{l}\text { BTZ025 } \\
1200^{\circ} \mathrm{C}\end{array}$ & 374 & 322 & 421 & 0.69 & 1.92 \\
\hline $\begin{array}{l}\text { BTZ025 } \\
1300^{\circ} \mathrm{C}\end{array}$ & 338 & 337 & 401 & 0.94 & 1.93 \\
\hline $\begin{array}{l}\text { BTZ025 } \\
1400^{\circ} \mathrm{C}\end{array}$ & 331 & 314 & 360 & 1.04 & 1.95 \\
\hline
\end{tabular}


$* \mathrm{~T}_{\mathrm{c}}=$ transition temperature or Curie temperature; $\mathrm{T}_{\mathrm{m}}=$ temperature at maximum permittivity; $\mathrm{T}_{\mathrm{cw}}=$ Temperature from which the permittivity starts to deviate from Curie-Weiss law; $T_{0}=$ Curie-Weiss temperature 
Table S4: Piezoelectric characteristics and density values of $\mathrm{BaZr}_{x} \mathrm{Ti}_{(1-x)} \mathrm{O}_{3}$ ceramics prepared by SHS and sintered by SPS ( $\mathrm{T}_{\mathrm{D}}$ values are indicated below samples ID). Literature data are also reported for the sake of comparison

\begin{tabular}{|c|c|c|c|c|c|}
\hline $\begin{array}{l}\text { Sample } \\
\text { ID }\end{array}$ & Density $\left(\mathrm{g} / \mathrm{cm}^{3}\right)$ & $Q_{m}$ & $k_{p}(\%)$ & $-d_{31}(\mathrm{pC} / \mathrm{N})$ & Ref \\
\hline $\begin{array}{l}\text { BTZ005 } \\
1200^{\circ} \mathrm{C}\end{array}$ & 5.43 & 181 & $11.5 \pm 0.5$ & $48.5 \pm 4.5$ & This work \\
\hline $\begin{array}{l}\text { BTZ005 } \\
1300^{\circ} \mathrm{C}\end{array}$ & 5.89 & 81 & $20 \pm 2$ & $87.5 \pm 2$ & This work \\
\hline $\begin{array}{l}\text { BTZ005 } \\
1400^{\circ} \mathrm{C}\end{array}$ & 5.57 & 79 & $17.5 \pm 0.5$ & $84 \pm 1$ & This work \\
\hline $\begin{array}{l}\text { BTZ010 } \\
1200^{\circ} \mathrm{C}\end{array}$ & 5.51 & 137 & 14 & $58 \pm 5$ & This work \\
\hline $\begin{array}{l}\text { BTZ010 } \\
1300^{\circ} \mathrm{C}\end{array}$ & 5.64 & 181 & $13 \pm 1$ & $56.5 \pm 3.5$ & This work \\
\hline $\begin{array}{l}\text { BTZ010 } \\
1400^{\circ} \mathrm{C}\end{array}$ & 5.47 & 57 & $19 \pm 1$ & $79.5 \pm 3.5$ & This work \\
\hline $\begin{array}{l}\text { BTZ015 } \\
1200^{\circ} \mathrm{C}\end{array}$ & 5.65 & 130 & $12 \pm 2$ & $38.5 \pm 2.5$ & This work \\
\hline $\begin{array}{l}\text { BTZ015 } \\
1300^{\circ} \mathrm{C}\end{array}$ & 5.77 & 196 & $11.5 \pm 0.5$ & $41.5 \pm 1.5$ & This work \\
\hline $\begin{array}{l}\text { BTZ015 } \\
1400^{\circ} \mathrm{C}\end{array}$ & 5.78 & 138 & $13.5 \pm 05$ & $56 \pm 1$ & This work \\
\hline $\begin{array}{l}\text { BTZ020 } \\
1200^{\circ} \mathrm{C}\end{array}$ & 5.38 & 193 & $10.5 \pm 0.5$ & $30 \pm 1$ & This work \\
\hline $\begin{array}{l}\text { BTZ020 } \\
1300^{\circ} \mathrm{C}\end{array}$ & 5.50 & 128 & $12.5 \pm 1.5$ & $43 \pm 6$ & This work \\
\hline $\begin{array}{l}\text { BTZ020 } \\
1400^{\circ} \mathrm{C}\end{array}$ & 5.84 & 178 & $11.5 \pm 0.5$ & $37.5 \pm 1.5$ & This work \\
\hline $\begin{array}{l}\text { BTZ020 } \\
1100^{\circ} \mathrm{C}\end{array}$ & 5.83 & 312 & 25 & 126 & [23] \\
\hline $\begin{array}{l}\text { BTZ005 } \\
1500^{\circ} \mathrm{C}\end{array}$ & 5.80 & - & - & 64 & [39] \\
\hline $\begin{array}{l}\text { BTZ004 } \\
1450^{\circ} \mathrm{C}\end{array}$ & 5.86 & 180 & 42.1 & 90 & [40] \\
\hline
\end{tabular}




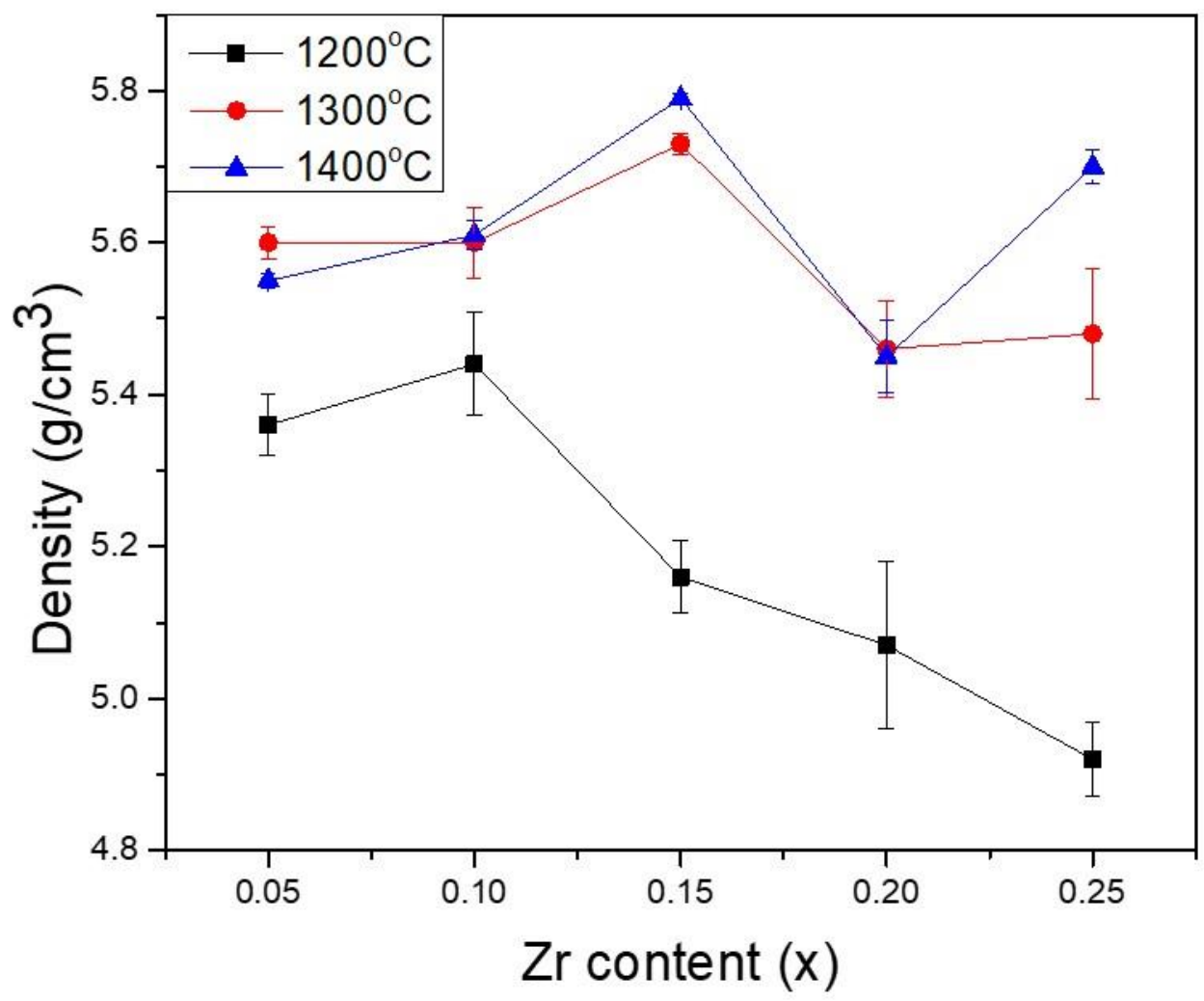

Figure S1: Density of post-annealed BTZ ceramics $\left(\mathrm{T}_{\mathrm{D}}=1200-1400^{\circ} \mathrm{C}\right)$ as a function of $\mathrm{Zr}$ content. 


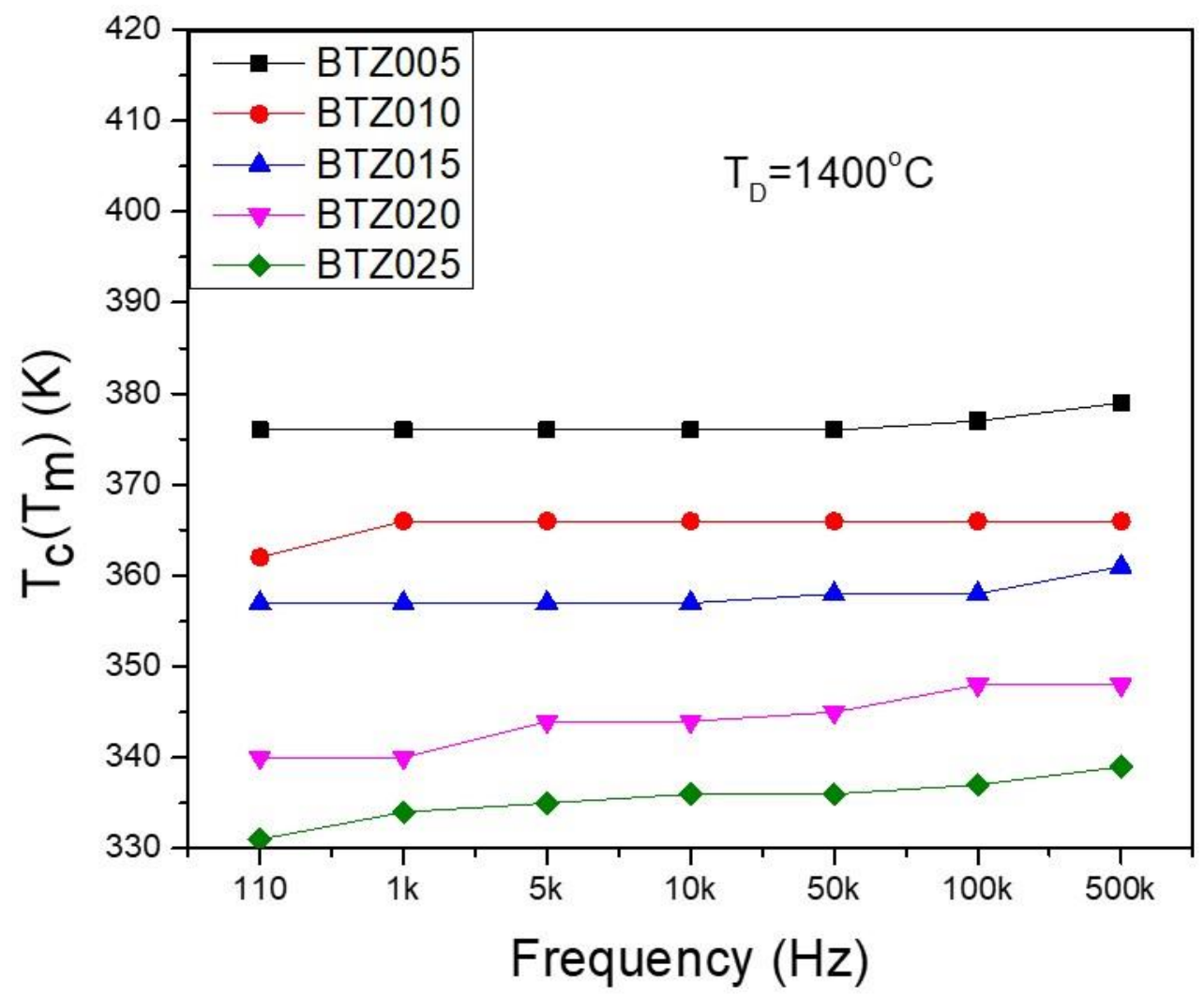

Figure S2: Curie temperature as a function of frequency for different BTZ compositions $\left(T_{D}\right.$ $\left.1400^{\circ} \mathrm{C}\right)$. 

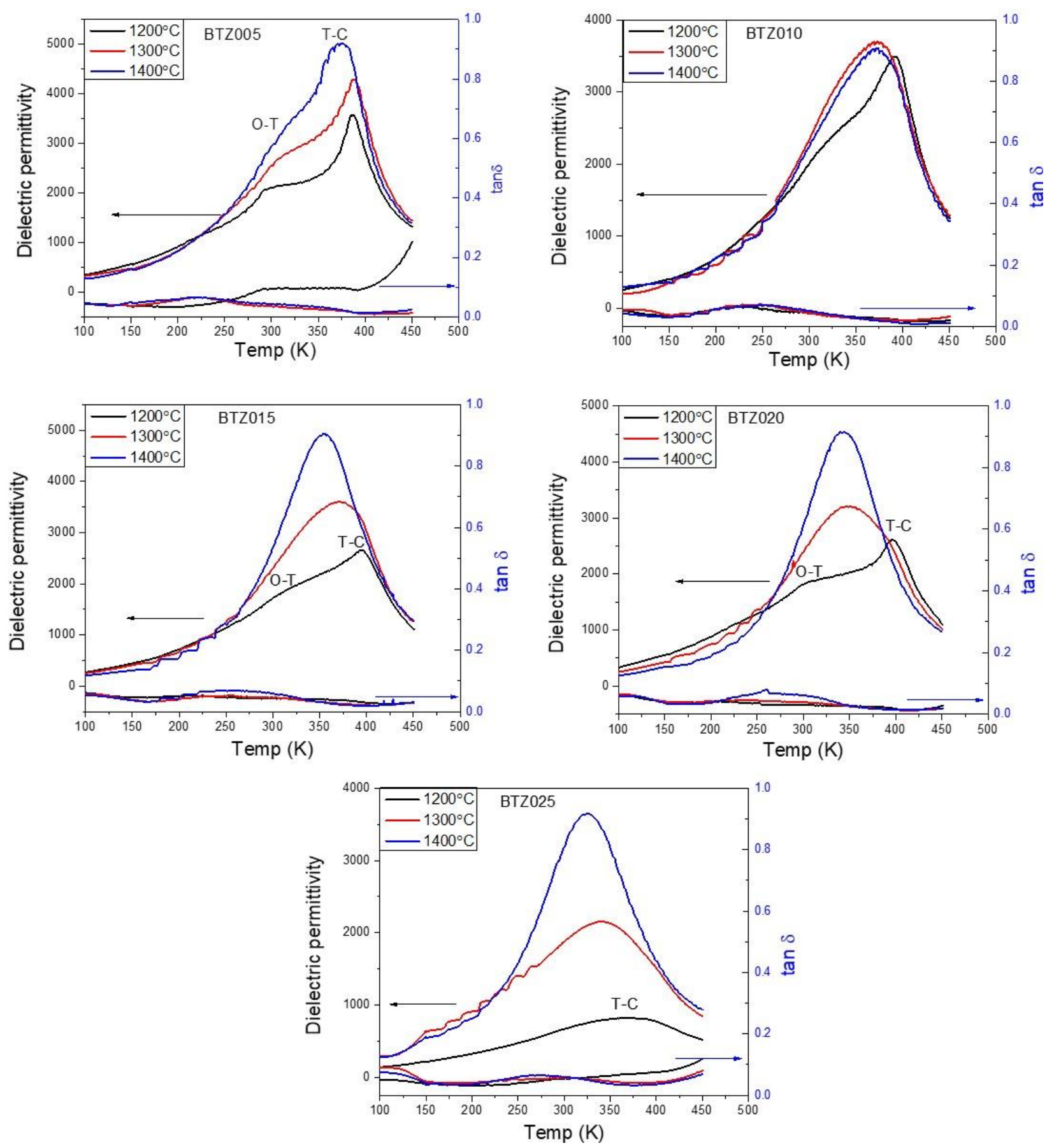

Fig. S3: Dielectric constant and loss of $\mathrm{BaZr}_{x} \mathrm{Ti}_{(1-x)} \mathrm{O}_{3}(x=0.05-0.25)$ ceramics at $1 \mathrm{kHz} .(\mathrm{O}=$ orthorhombic; $\mathrm{T}=$ tetragonal; $\mathrm{C}=$ cubic phase transition). 

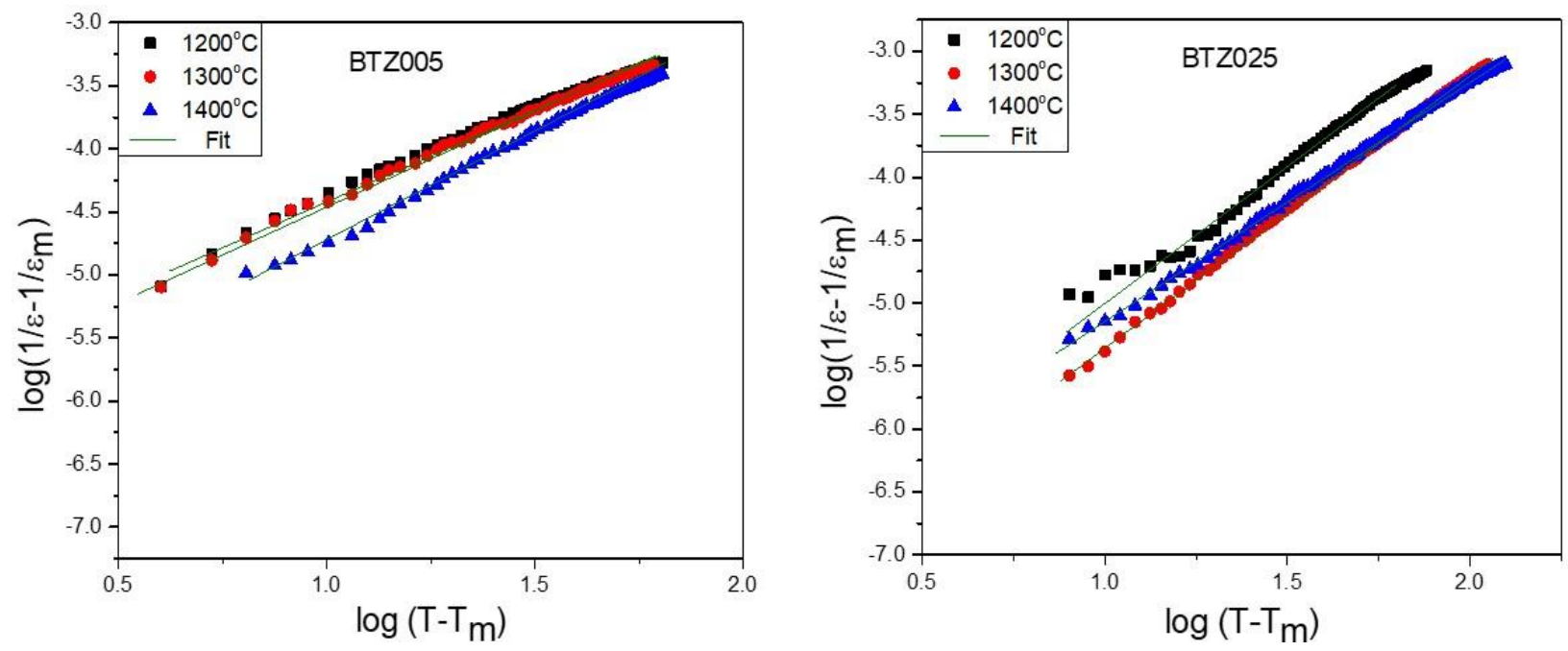

Fig. S4: Plots of $\log \left(\frac{1}{\varepsilon}-\frac{1}{\varepsilon_{m}}\right)$ versus $\log \left(T-T_{m}\right)$ for BTZ005 and BTZ025 compositions. 


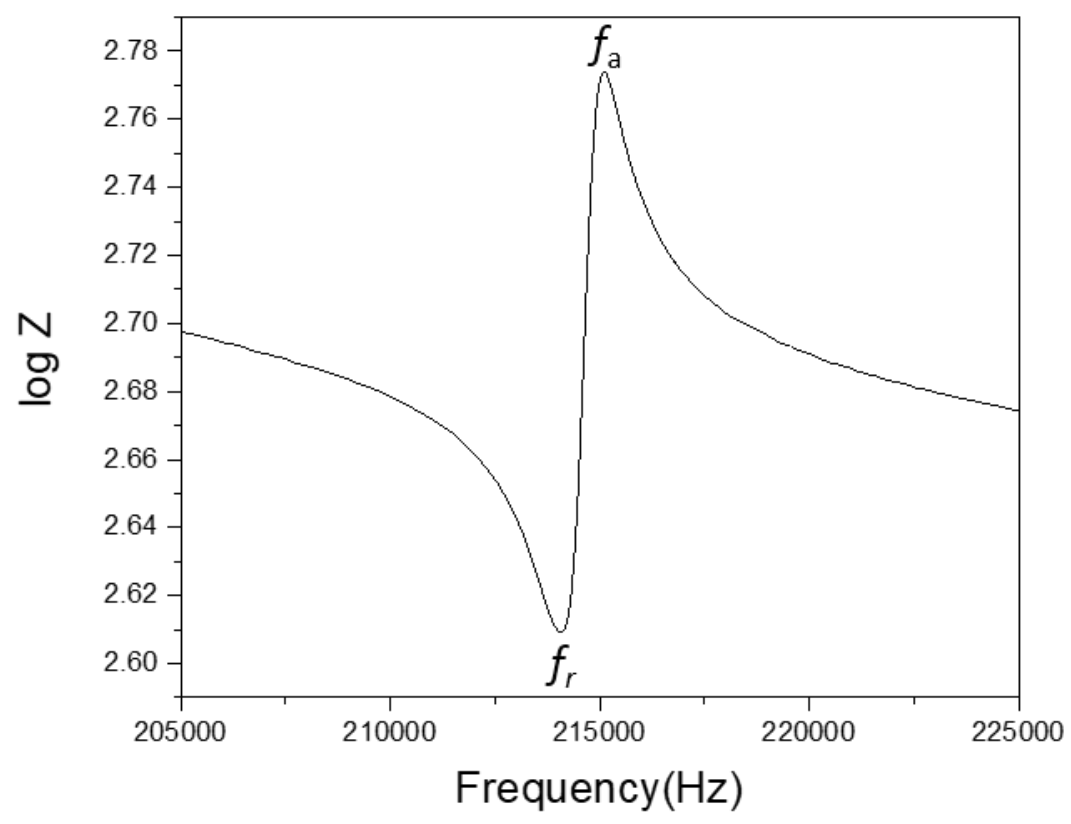

Fig. S5: Impedance as a function of frequency, showing the resonance $\left(f_{r}\right)$ and antiresonance $\left(f_{a}\right)$ frequencies, relative to BTZ005 ceramics sintered at $1300^{\circ} \mathrm{C}$. 